\title{
Polar substorm on 7 December 2015: preonset phenomena and features of auroral breakup
}

\author{
Vladimir V. Safargaleev ${ }^{1}$, Alexander E. Kozlovsky ${ }^{2}$, and Valery M. Mitrofanov ${ }^{1}$ \\ ${ }^{1}$ Polar Geophysical Institute, Apatity, Russia \\ ${ }^{2}$ Sodankylä Geophysical Observatory, Sodankylä, Finland \\ Correspondence: Vladimir V. Safargaleev (vladimir.safargaleev@ pgia.ru)
}

Received: 16 August 2019 - Discussion started: 25 September 2019

Revised: 4 May 2020 - Accepted: 22 June 2020 - Published: 28 July 2020

\begin{abstract}
Comprehensive analysis of a moderate $600 \mathrm{nT}$ substorm was performed using simultaneous optical observations inside the auroral oval and in the polar cap, combined with data from satellites, radars, and ground magnetometers. The onset took place near the poleward boundary of the auroral oval that is not typical for classical substorms. The substorm onset was preceded by two negative excursions of the interplanetary magnetic field (IMF) $B z$ component, with a 1 min interval between them, two enhancements of the antisunward convection in the polar cap with the same time interval, and 15 min oscillations in the geomagnetic $H$ component in the auroral zone. The distribution of the pulsation intensity along meridian has two local maxima, namely at the equatorial and poleward boundaries of the auroral oval, where pulsations occurred in the out-of-phase mode resembling the field line resonance. At the initial stage, the auroral breakup developed as the auroral torch stretched and expanded poleward along the meridian. Later it took the form of the largescale coiling structure that also distinguishes the considered substorm from the classical one. Magnetic, radar, and the Active Magnetosphere and Planetary Electrodynamics Response Experiment (AMPERE) satellite data show that, before the collapse, the coiling structure was located between two field-aligned currents, namely downward at the poleward boundary of structure and upward at the equatorial boundary. The set of GEOTAIL satellites and ground data fit to the near-tail current disruption scenario of the substorm onset. We suggest that the 15 min oscillations might play a role in the substorm initiation.
\end{abstract}

\section{Introduction}

\subsection{Location of substorm onsets as inferred from satellite and ground observations}

Although the substorm onset and development mechanisms were of high interest for many decades, there are still a number of issues under discussion. The substorm studies use satellite plasma and field measurements in the magnetotail plasma sheet and simultaneous auroral and magnetic observations on the ground in the auroral zone where the plasma sheet is mapped onto the ionosphere. One of the longstanding problems is where and when key substorm processes initiate. In the distant magnetotail, the direct comparison of satellite measurements and ground data is hindered by the low accuracy of the mapping of magnetospheric processes to the ionosphere that are conditioned by the complex shape of geomagnetic field lines. In particular, the causal link between the formation of so-called auroral poleward boundary intensifications (PBIs) and distant reconnections (e.g., Lyons et al., 1999) is very difficult to test. Note that some kind of PBI is regarded as a substorm-onset trigger (Nishimura et al., 2015). To solve the above problem, one needs either an appropriate modification of the geomagnetic field model (Brito and Morley, 2017) or the involvement of some additional information (e.g., Shevchenko et al., 2010) to perform a more or less accurate conjugation of the satellite with ground instruments.

Two competing substorm scenarios based on in-space observations have been proposed. The first one implies that the substorm originates in the near-Earth portion of the plasma sheet due to the dawn-to-dusk current disruption (CD) around $10 R_{\mathrm{E}}$ in the course of the development of some 
kind of magnetohydrodynamic (MHD) or kinetic instability (e.g., Lui, 1996). In particular, the ballooning instability (e.g., Roux et al., 1991) may cause current disruption in a localized region of the plasma sheet. As a result, the current wedge is formed, and the auroral structure in the form of a westwardtraveling surge develops, and the magnetic field is dipolarized. In accordance with the second scenario (e.g., Baker et al., 1996), the substorm starts at 20-30 $R_{\mathrm{E}}$ as a result of magnetic reconnection via near-Earth neutral line (NENL) formation. In ionospheric projections, the closer substorms are associated with maximal geomagnetic disturbances (negative bays in the $H$ component) deep inside the auroral zone, whereas distant substorms should be displayed as negative bays with maximum amplitude at higher latitudes (close to the poleward boundary of the auroral zone).

Two types of the ground substorm onsets that map into the inner and mid-tail were described by Baker et al. (1993) and Pulkkinen et al. (1998). According to the interpretation of the authors, both types of onsets are initiated by NENL formation. Another point of view is that both $\mathrm{CD}$ and reconnection may operate, producing different types of substorm onsets in two different latitudinal zones on the ground (Vasyliunas, 1998). Kleimenova et al. (2012) proposed distinguishing the substorms associated with magnetic bays near the poleward boundary of the auroral oval (i.e., polar substorms) from those that start inside the auroral zone and then expand poleward (further referred to as classical substorms). The statistics show that polar substorms are observed preferentially in the premidnight zone, and, indeed, $20 \%$ of substorms may be classified as polar (Kleimenova et al., 2012). Similar to the classical substorm, the polar substorm is accompanied by Pi2 geomagnetic pulsations and auroral breakup. However, the latter occurs as a large-scale vortex (Kleimenova et al., 2012) or a poleward-progressing auroral torch-like structure (Safargaleev et al., 2018) rather than an auroral bulge or westward-traveling surge (WTS) in the classical substorm onset.

Sometimes substorms occur as a sequence when a clear growth phase is followed by the first onset at lower latitudes, and the second one involves all latitudes between $60^{\circ}$ and $70^{\circ}$ (e.g., Mishin et al., 2001). In the case presented by Safargaleev et al. (2018), the intense polar substorm developed in the background of rather weak substorm-like disturbances at lower latitudes. Disturbances started 15-20 min prior to the polar substorm onset and may be identified in the westward electrojet.

\subsection{Substorm triggers}

Baker et al. (1996) noticed that multiple onsets occur often. If they occur before the main breakup, they are called pseudobreakups (e.g., Koskinen et al., 1993). After the main onset, they are called intensifications. Pseudobreakups look similar to substorm expansion but are relatively weaker. Some re- searchers believe that pseudobreakups may be regarded as a substorm trigger (e.g., Rostoker, 1968).

The substorm trigger in the interplanetary medium is one more issue under discussion. Substorms may be initiated by variations in solar wind dynamic pressure (sudden impulses SIs) or the interplanetary magnetic field (IMF). It was found that the majority of SI events do not lead to substorms (Liou et al., 2017, and references therein). Variations in the IMF $B z$ component seem to be more effective. Russell (2000) suggested that double substorm onsets can be caused by a temporal deflection of northward IMF southwards. In the review by Baker et al. (1996) it was noted that a class of substorms were triggered by positive changes in $B z$ after it turned southward. Mishin et al. (2001) showed, with the superimposed epoch analysis, that substorm-associated $B z$ variation is a gradual change, first to negative and then to positive values, and it looks like a fragment of sinusoid. As a rule, the abovementioned fluctuations are easily identified in IMF data due to large amplitude and timescale, or they can be inferred by statistics. Recently, Safargaleev et al. (2018) proposed that the polar substorm might be initiated by the less prominent sinusoid-like variation in the IMF $B z$ component with a period of $\sim 15$ min detected in the solar wind several tens of minutes prior to the onset. To associate substorm onset with these kinds of IMF variations, one needs careful estimating of the time delay between the arrival of the IMF irregularity at the magnetopause and the beginning of the substorm.

The magnetospheric response time to the variation in the solar wind can vary from a few minutes to several hours. Hairston and Heelis (1995) observed a time lag of 17-25 min in the ionospheric flows responding to the IMF changing from north- to southward. In accordance with the numerical simulation of Bargatze et al. (1999), the substorm occurs 30$60 \mathrm{~min}$ after the solar wind energy input (i.e., after a southward turning of the IMF and a dayside reconnection beginning). This means that the time lag between the convection response and the substorm onset might be about $30 \mathrm{~min}$. One more important but uncertain (within 5-25 min) parameter is the propagation time of solar wind between the bow shock and dayside magnetopause. Samsonov et al. (2017) showed that the typical time for a southward interplanetary magnetic field turning to propagate across the dayside magnetosheath to subsolar magnetopause is $14 \mathrm{~min}$.

\subsection{Preonset phenomena}

Auroral activity at high latitudes contains information about magnetospheric processes. For this reason, a number of optical studies were focused on the magnetospheric phenomena prior to the substorms and aimed to find out the precursors of substorms. Pellinen and Heikkila (1978) and Baumjohann et al. (1981) showed that the breakup is preceded by the preexisting arc fading after its short brightening. Safargaleev and Osipenko (2001) noted that the fading and/or brightening of multiple preexisting arcs looks like the poleward displace- 
ment of the auroral activity, which may be considered as an ionospheric trace of the waves propagating tailward in the plasma sheet. Much attention was paid to the nearly northsouth aligned auroral structures originating at the poleward auroral boundary and progressing to lower latitudes, which were considered as substorm precursors (e.g., Rostoker et al., 1987). Golovchanskaya et al. (2015) focused on the wavelike signatures of the east-west type of auroral activities, which appear before the breakup and may be related to ballooning waves propagating in the plasma sheet. In fact, any form of optical presubstorm activity could be considered as a precursor of the onset, so such investigations need to continue to clarify the situation.

\subsection{Objectives of the study}

The main aim of the present paper is a detailed multiinstrumental investigation of a case of the polar substorm on 7 December 2015.

First, we describe the main features of the polar substorm inferred from ground observations to show that the most intense onset begins near the poleward boundary of the auroral oval so that the preceding onset-like features at lower latitudes look like pseudobreakup events (Sect. 3.1). In order to avoid discussing whether they are pseudobreakups or not, we use a general term in the text, namely preonset phenomena.

Second, we show signatures of preonset phenomena in the ionospheric radar data (Sect. 3.2) and in the solar wind (Sect. 3.3).

Third, we emphasize the differences between polar and classical substorms in the auroral data (Sect. 4.1) and the distribution of large-scale field-aligned currents (Sect. 5.2).

Fourth, we present GEOTAIL satellite data to show that, in the case considered, the current disruption in the plasma sheet is more probable reason for the substorm onset than the neutral line formation (Sect. 4.2).

Fifth, we discuss the possible role of two structures separated by $15 \mathrm{~min}$ in the IMF, ionospheric plasma flow, and magnetic and optical data in the substorm process (Sect. 5.3)

Finally, we discuss possible mechanisms matching the observations (Sect. 5.4).

\section{Instrumentation}

The study utilizes data from the IMAGE magnetometer network (Tanskanen, 2009). Small black circles on the map in Fig. 1 show the locations of the magnetometers. The time resolution of the data is $10 \mathrm{~s}$. The time of the substorm onset was defined as the beginning of a negative deviation in the $H$ component first detected at Bear Island $\left(\mathrm{BJN} ; 74.50^{\circ} \mathrm{N}\right.$, $19.20^{\circ} \mathrm{E}$, geomagnetic latitude $71.27^{\circ} \mathrm{N}$ ) at $T_{0} \sim 17: 30 \mathrm{UT}$. We used the Altitude-Adjusted Corrected Geomagnetic (AACGM) coordinates (https://ccmc.gsfc.nasa.gov/requests/ instant/instant_aacgm.php?model=AACGM\&type $=1$, last

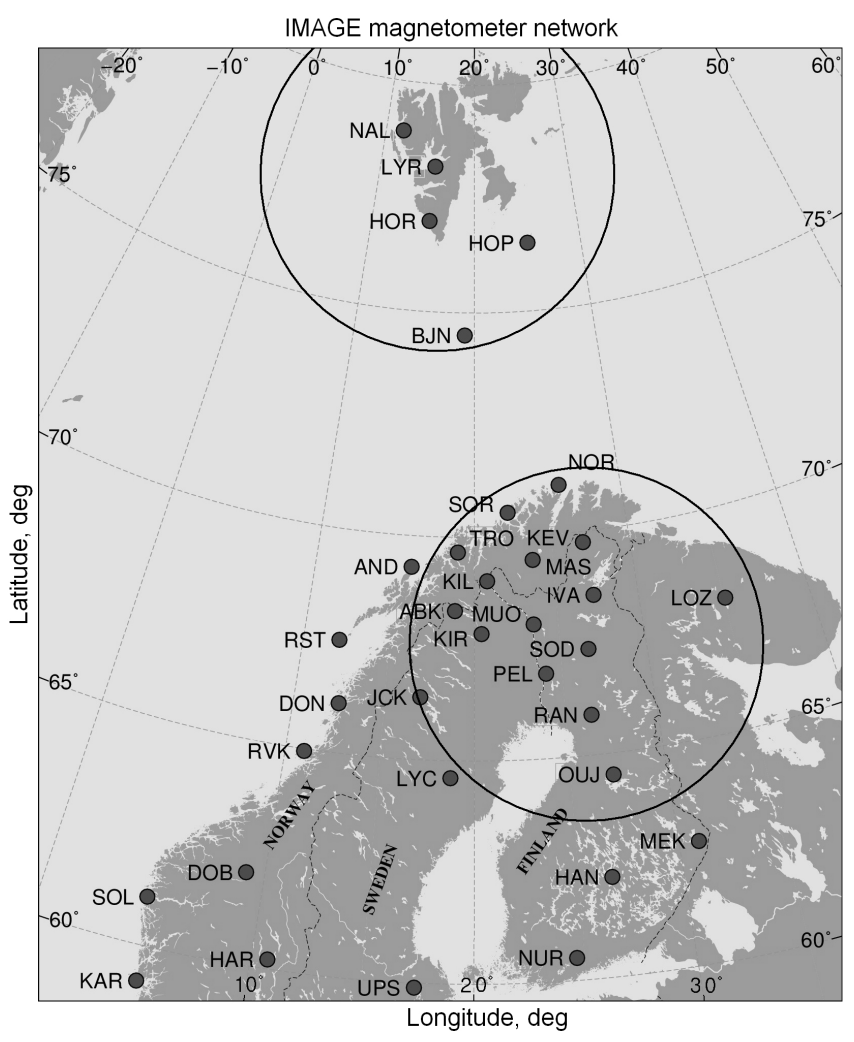

Figure 1. Observatories of the IMAGE magnetometer network (small black dots). Large circles show the field of view of the all-sky cameras in Barentsburg (BAB; top) and Sodankylä (SOD; bottom).

access: 16 March 2020). In addition to the magnetograms, we used data of the ionospheric equivalent currents provided in frame of the ECLAT project (Amm and Viljanen, 1999; Pulkkinen et al., 2003). The equivalent currents are virtual currents in the ionospheric plane causing the same magnetic field change on the ground as the real 3D ionospheric and/or magnetospheric current system. In the equivalent current map, footprints of the localized downward (upward) field-aligned current (FAC) can often be associated with quasi-circular clockwise (counterclockwise) equivalent current vortices around the location of the upward (downward) FAC (e.g., Amm et al., 2002; Palin et al., 2016).

Two all-sky cameras (ASCs) located in Barentsburg $\left(\mathrm{BAB} ; 78.09^{\circ} \mathrm{N}, 14.21^{\circ} \mathrm{E}\right.$; geomagnetic latitude $\left.75.07^{\circ} \mathrm{N}\right)$ and Sodankylä (SOD; $67.37^{\circ} \mathrm{N}, 26.63^{\circ} \mathrm{E}$; geomagnetic latitude $63.70^{\circ} \mathrm{N}$ ) monitored auroral activity. The BAB camera was operating in visible light and provides one frame per second. Green line images from the SOD camera, at 3-10 s resolution, were used in the study. Large circles in Fig. 1 show the fields of view of the cameras at a height of $110 \mathrm{~km}$ for elevation angles above $15^{\circ}$. The ASC keograms in Fig. 2 were made along the geomagnetic meridian.

The WIND satellite and two satellites of the Time History of Events and Macroscale Interactions during Substorms 

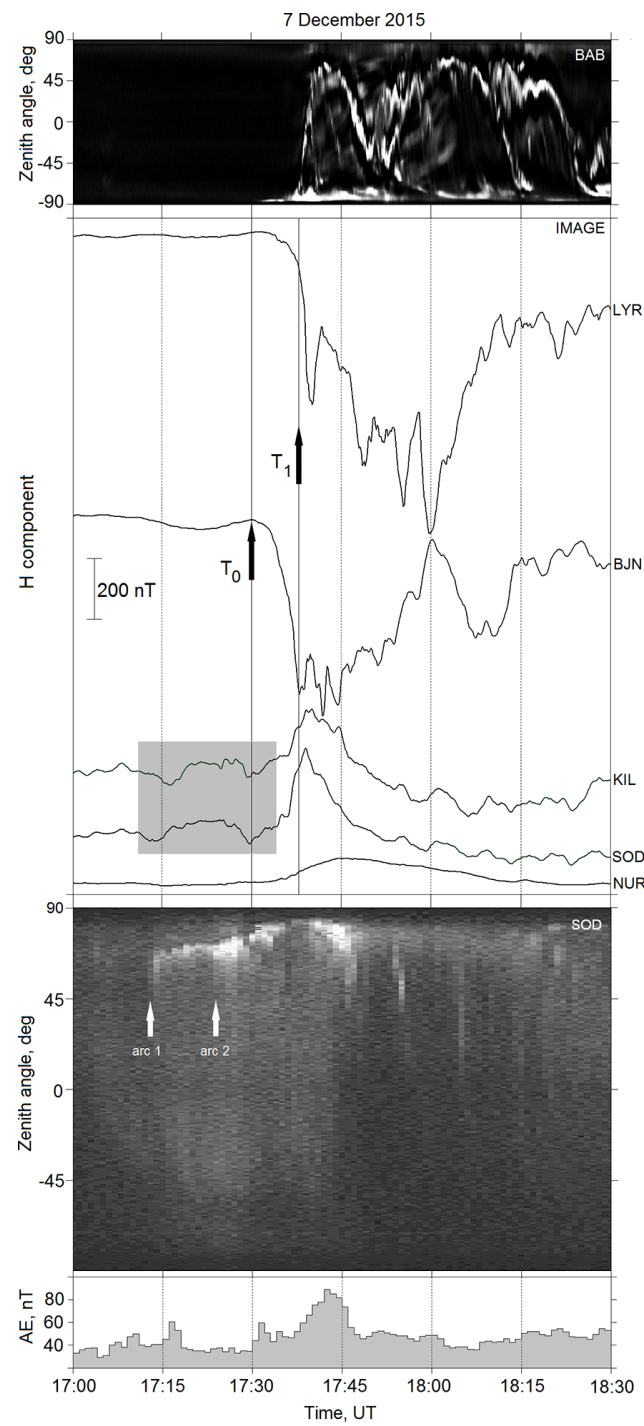

(a)

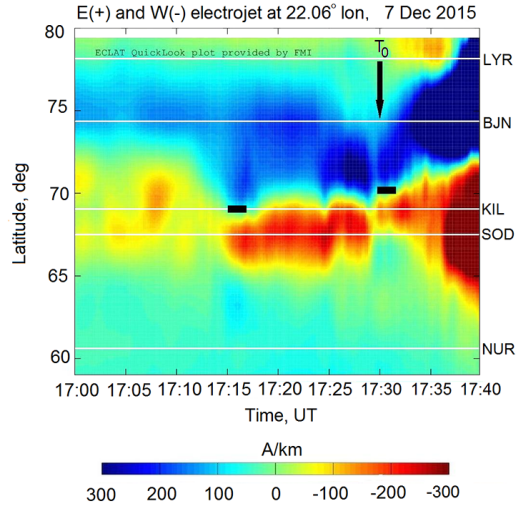

(b)

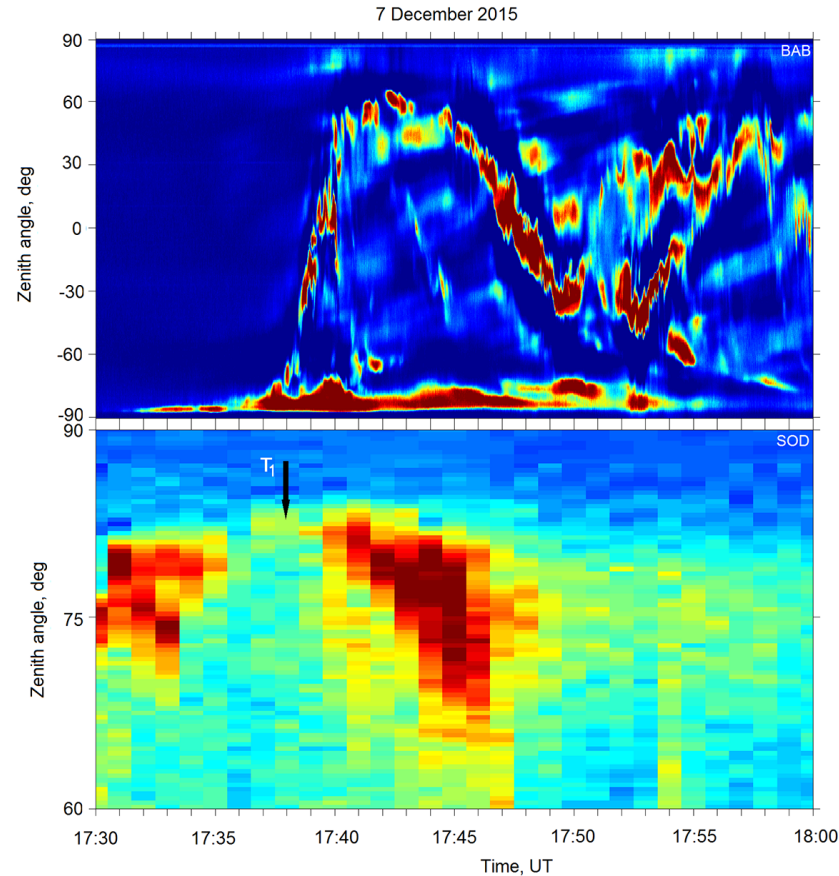

(c)

Figure 2. (a) Keograms showing aurora dynamics over Barentsburg (BAB) and Sodankylä (SOD) and magnetic activity on the ground, as inferred from five observatories of the IMAGE magnetometer network and Auroral Electrojet (AE) index. (b) Dynamics of equivalent ionospheric currents; westward and eastward electrojets are indicated with gradations of blue and red, respectively, and white horizontal lines show the latitude of the observatories. (c) Keograms of SOD and BAB at a higher temporal resolution in color. $T_{0}$ and $T_{1}$ are the times of onset and torch formation, respectively. Two negative variations in the $H$ component are highlighted in gray.

(THEMIS) mission, (namely THB and THC) provided the IMF and solar wind data. This allowed us to estimate interplanetary conditions at the bow shock. The GEOTAIL satellite monitored dawnside plasma sheet parameters (DMSPs) and was magnetically conjugated to the region of the groundbased observations. The DMSP F18 measurement of precipitating particles $20 \mathrm{~min}$ before the onset allowed us to estimate the location of the BJN station as being close to the poleward boundary of the auroral oval. Data from the Active Magnetosphere and Planetary Electrodynamics Response Experiment (AMPERE) satellite were used to support conclusions regarding field-aligned current distribution in the area of optical observations.

The European Incoherent Scatter (EISCAT) Svalbard Radar (ESR) is located near Longerbyen (LYR; $78.2^{\circ} \mathrm{N}$, $15.8^{\circ} \mathrm{E}$; geomagnetic latitude $75.05^{\circ} \mathrm{N}$ ) and is about $40 \mathrm{~km}$ east of the BAB ASC. The ESR provided the height profile of the ionospheric parameters (electron density, electron, and ion temperatures and the ion line-of-sight velocity) at a $1 \mathrm{~min}$ resolution. Data from the Super Dual Auroral Radar Network (SuperDARN) were used for monitoring the ionosperic plasma flow. At the F-region heights, the Doppler shift of received signals gives the line-of-sight component of the con- 

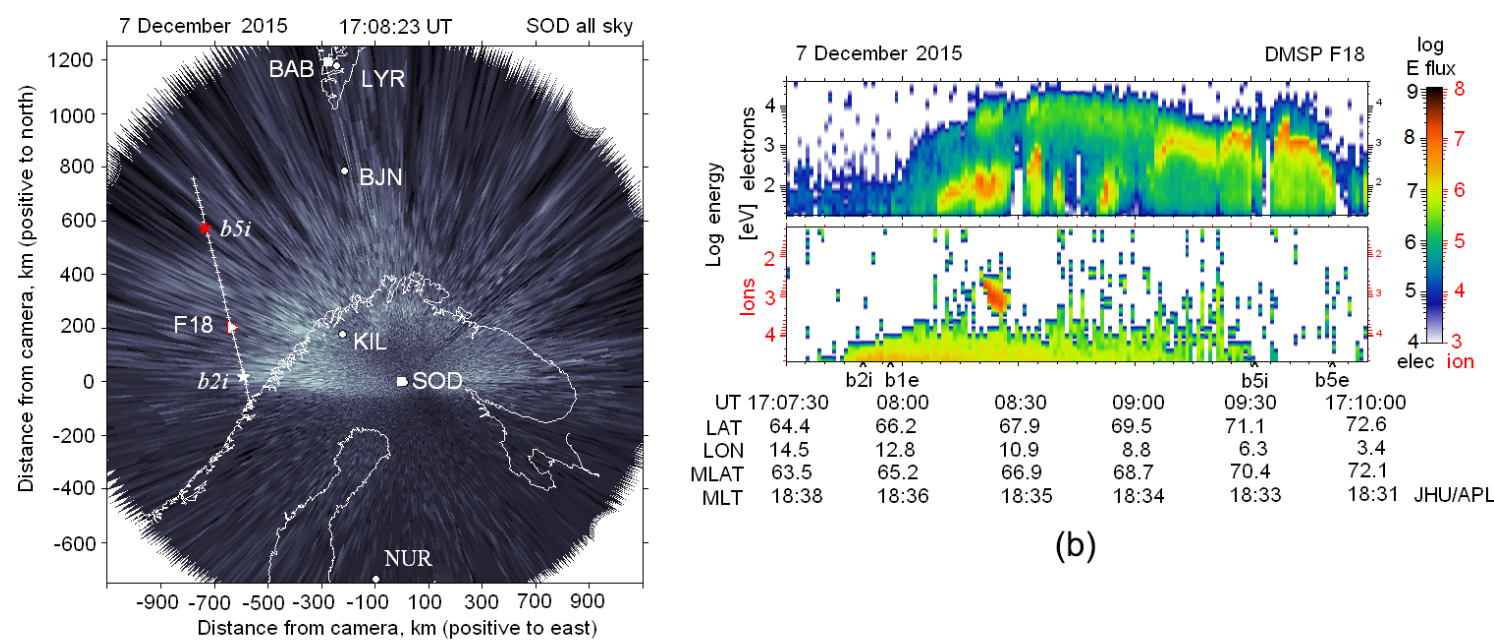

(b)

(a)

Figure 3. (a) Sodankylä (SOD) all-sky camera image at $557.7 \mathrm{~nm}$. North is at the top, and west is on the left. The DMSP F18 trajectory is mapped, and the triangle marks the location of the satellite at the time of the image. (b) DMSP spectrograms with the magnetospheric boundaries identified using the algorithms of Newell et al. (1996).

vection velocity. A detail description of the system was given by Greenwald et al. (1995) and Chisham et al. (2007).

\section{Preonset activity}

\subsection{General overview of magnetic and auroral activity}

The event took place during a moderate geomagnetic activity (Dst $\sim-10 \mathrm{nT} ; \mathrm{Kp} \sim 2+$ ). No magnetic storms occurred 1 week before and after the event. Variations of the geomagnetic $H$ component at IMAGE stations, the auroral activity above northern Scandinavia and Spitsbergen, and the equivalent ionospheric currents (electrojets) are shown in Fig. 2. The substorm started at $T_{0} \sim$ 17:30 UT $(\sim 19$ :30 Magnetic Local Time - MLT) as a strong negative deviation of about $\sim-600 \mathrm{nT}$, first seen at BJN (Fig. 2a; middle panel), and poleward displacement of the westward electrojet in Fig. 2b (top panel). A few minutes later a positive bay with amplitude $\sim+250 \mathrm{nT}$ was detected at Kilpisjärvi (KIL) and SOD. Moreover, noticeable positive variations were seen at the mid- and low-latitude stations of Nurmijärvi (NUR; Fig. 2a) and Alibag (ABG; see Sect. 4.2), respectively. While negative variations in the $H$ component should be caused by a change in the westward ionospheric current, positive deflections at subauroral latitudes indicate the ionospheric current of the opposite direction over SOD. Indeed, both currents are seen in Fig. $2 b$.

The auroral-spatial distribution is presented by the keograms in Fig. 2a and c. No distinct auroras were seen within the field of view of the BAB all-sky camera until the onset. Most likely, BAB was in the polar cap at that time. The prevailing auroras over SOD were diffuse auroras which the equatorial edge moved from the zenith toward the south- ern horizon from 17:00 UT till the moment $T_{0}$. This means that, just before the breakup, SOD was inside the auroral oval close to its equatorial boundary. The position of IMAGE stations relative to the poleward boundary of auroral oval may be estimated from the DMSP F18 data under assumption that the boundary is oriented along the geomagnetic latitude. The ionospheric projection of the DMSP trajectory $20 \mathrm{~min}$ before the substorm onset is shown in Fig. 3a. In accordance with Newell et al. (1996), the poleward boundary of the main auroral oval is determined as an abrupt drop in the electron energy flux (b5e boundary in Fig. 3b). In Fig. 3a, the footprint of this boundary is marked by the yellow asterisk. Its geomagnetic latitude is $71.4^{\circ} \mathrm{N}$, which is slightly poleward to BJN $\left(71.27^{\circ} \mathrm{N}\right)$. At $T_{0}$, BJN was located inside the auroral oval in the vicinity of its poleward boundary. Following Kleimenova et al. (2012), the event can be considered to be a polar substorm. Note that the boundary of the diffuse aurora, which is well seen in Fig. 3a, may be associated with an ion-isotropic boundary ( $b 2 i$ - boundary on the DMSP spectrogram). In Fig. 3a, the footprint of this boundary is marked by the open asterisk.

The auroral breakup started at about $T_{0}$ as 1 min of fading and then brightening of the preexisting auroral arc observed by the SOD all-sky camera at the zenith angle $\sim+75^{\circ}$, i.e., about $400 \mathrm{~km}$ north of Sodankylä. Such behavior of auroras is typical for the beginning of a substorm (e.g., Pellinen and Heikkila, 1978). At about the same time, active auroras appeared on the southern horizon of the BAB ASC, more than $600 \mathrm{~km}$ south of Barentsburg. These auroras are better seen on the upper keogram in Fig. 2c from 17:31:30 UT. Although both cameras observed enhanced luminosity somewhere in the vicinity of BJN because of the large zenith angles, we cannot say for sure whether this is the same arc. In the course 

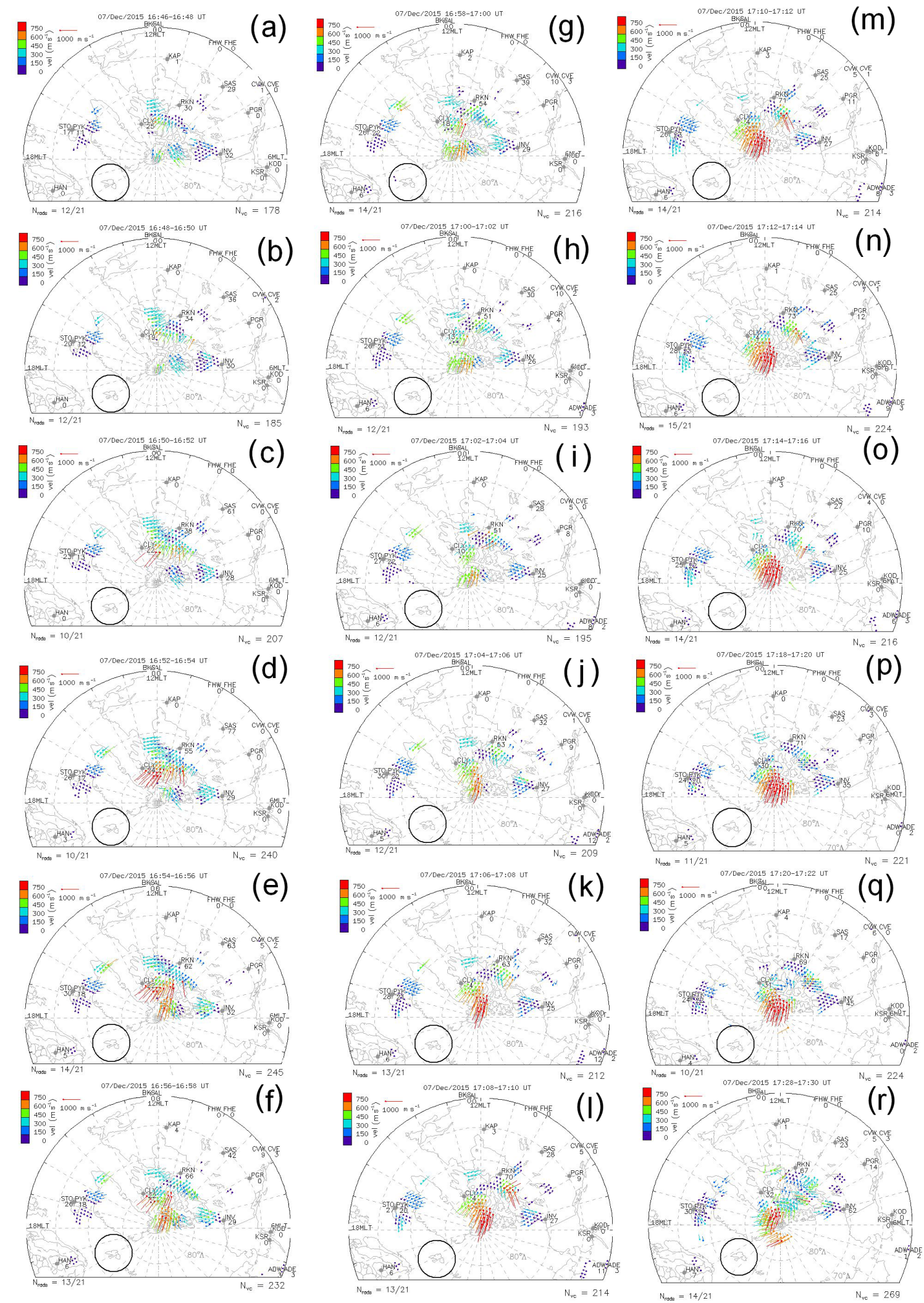

Figure 4. Series diagrams showing global convection patterns averaged over $2 \mathrm{~min}$. Gridded line-of-sight velocity vectors are plotted at points where velocity data were provided by measurements. Large circles border the working field of view of the all-sky camera in Barentsburg (BAB). 
of the breakup development, the poleward boundary of auroras in $\mathrm{BAB}$ continued the poleward movement, whereas the equatorial edge of discreet auroras in SOD moved in opposite directions (Fig. 2c).

\subsection{Preonset phenomena in the data of ground-based observations}

The substorm was preceded by two negative bays in the $H$ component at KIL and SOD at a separation of about $15 \mathrm{~min}$ (interval is indicated in gray in Fig. 2a) Note, that the variations are also seen in $\mathrm{AE}$ index. In general, variation in the fragment is reminiscent of sinusoid and, for brevity, hereinafter we will use the term "repetition period" for the interval between two consecutive extremes (maxima or minima). These negative declinations were associated with equatorward expansion and/or displacement and enhancement of the westward electrojet (Fig. 2b). At this time, the westward electrojet was about 3 times stronger than the eastward electrojet. Moreover, two enhancements and the slight poleward displacement of discrete auroras ( $\operatorname{arc} 1$ and arc 2) took place in SOD (Fig. 2a; bottom keogram). The enhancements started at nearly same time as the negative variations in SOD, at 17:13 and 17:24 UT, respectively. These moments are shown in the keogram with white arrows. The presumable location of the arc 1, with respect to the electrojets at 17:15 UT, is shown in Fig. $2 b$ with black rectangle. The features listed above might indicate a pseudobreakup; however, we will use the term "prebreakup phenomena" below instead of pseudobreakup.

A total of 18 SuperDARN diagrams in Fig. 4 show signatures of the large-scale ionospheric plasma flow. As mentioned in the Introduction, the time lag between the convection response and substorm onset might be about $30 \mathrm{~min}$. In such a case, one should look for related convection features $30 \mathrm{~min}$ before $T_{0}$, i.e., around 17:00 UT. It is probable that such a feature is the enhancement of the plasma flow in the polar cap that started at 17:04 UT, reached maximum at 17:08-17:10 UT (diagram $i$ in Fig. 4), and lasted until $T_{0}$. One more flow enhancement took place at 16:52 UT, i.e., 15 min before the first one (diagram $d$ in Fig. 4). We suggest that the time lag and the close repetition period $(\sim 15 \mathrm{~min})$ indicate a relationship of the flow enhancements and the magnetic and optical prebreakup events.

The first flow enhancement was observed near noon at 78$85^{\circ}$ geographic latitude (GLAT; diagram $b$ in Fig. 4). This location corresponds to the ionospheric projection of the mantle (Newell and Meng, 1992). This increase in antisunward convection might be caused by the enhancement of the dayside reconnection under negative IMF $B z$.

Just before $T_{0}$, one of the SuperDARN radars detected the enhancement of a convective stream toward Spitsbergen (Fig. 4r). In Fig. 5 we present the altitude profiles of the electron density and ion temperature over Spitsbergen measured by ESR, where time $T_{0}$ is indicated by a white arrow. The in-

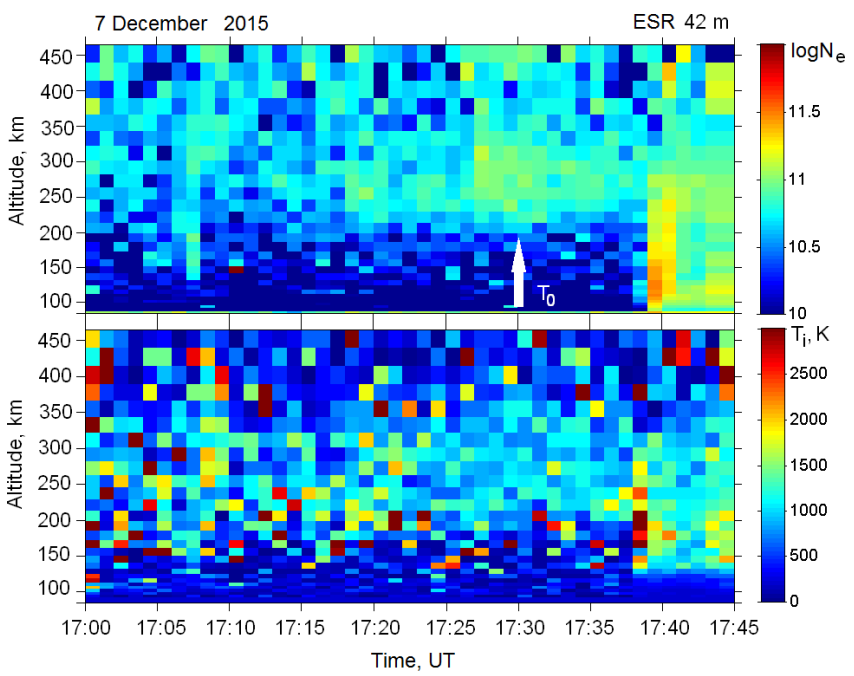

Figure 5. Data of the EISCAT Svalbard Radar (ESR) at Longerbyen, with the electron density $N_{\mathrm{e}}$ and ion temperature $T_{\mathrm{i}} . N_{\mathrm{e}}$ enhancement at 17:39 UT was associated with the coiling structure arriving at the beam.

crease in the F-region electron density at about $T_{0}$ looks like a signature of the polar patch associated with the reconnected flux tubes drifting across the polar cap from the cusp to the magnetotail (e.g., Lockwood and Carlson, 1992). Assuming that the patch originated in the cusp region at the moment of the first flow enhancement, one determines the patch propagation time from the cusp to the ESR beam to be $\sim 40 \mathrm{~min}$. Buchau et al. (1983) showed that patches drift antisunward with the background plasma flow $\left(\sim 1000 \mathrm{~m} \mathrm{~s}^{-1}\right.$ estimated from SuperDARN for the case considered). Thus, the distance between the patch origin and place of patch detection is about $2500 \mathrm{~km}$, which corresponds approximately to the distance between the statistical cusp position and the ESR beam.

The appearance of the polar patch in the radar data and the equatorward shift of westward electrojet (Fig. 2b) happened to occur at the same time. Assuming the patch to be the footprint of one of the reconnected flux tubes, we suppose that the jet displacements could be a sequence of the expansion of the magnetospheric lobe caused by reconnected flux tubes arriving from the dayside.

\subsection{Preonset phenomena in the interplanetary space}

Positions of the satellites measuring interplanetary parameters (THB, THC, and WIND) are shown in Fig. 6a. The satellite coordinates and the bow shock and magnetopause locations were obtained via the interactive visualization of satellite orbits tool (4D Orbit Viewer) available from the CDAWEB system. From the THEMIS satellite data, we have obtained about $650 \mathrm{~km} \mathrm{~s}^{-1}$ propagation velocity of the IMF features indicated by the shading in Fig. 6b. This corresponds to the solar wind speed measured at the WIND satellite. 


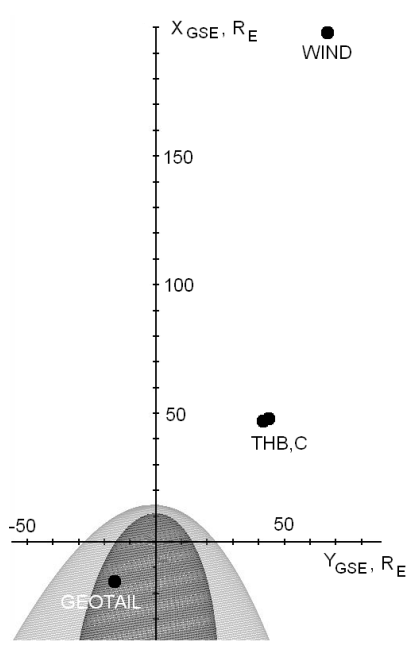

(a)

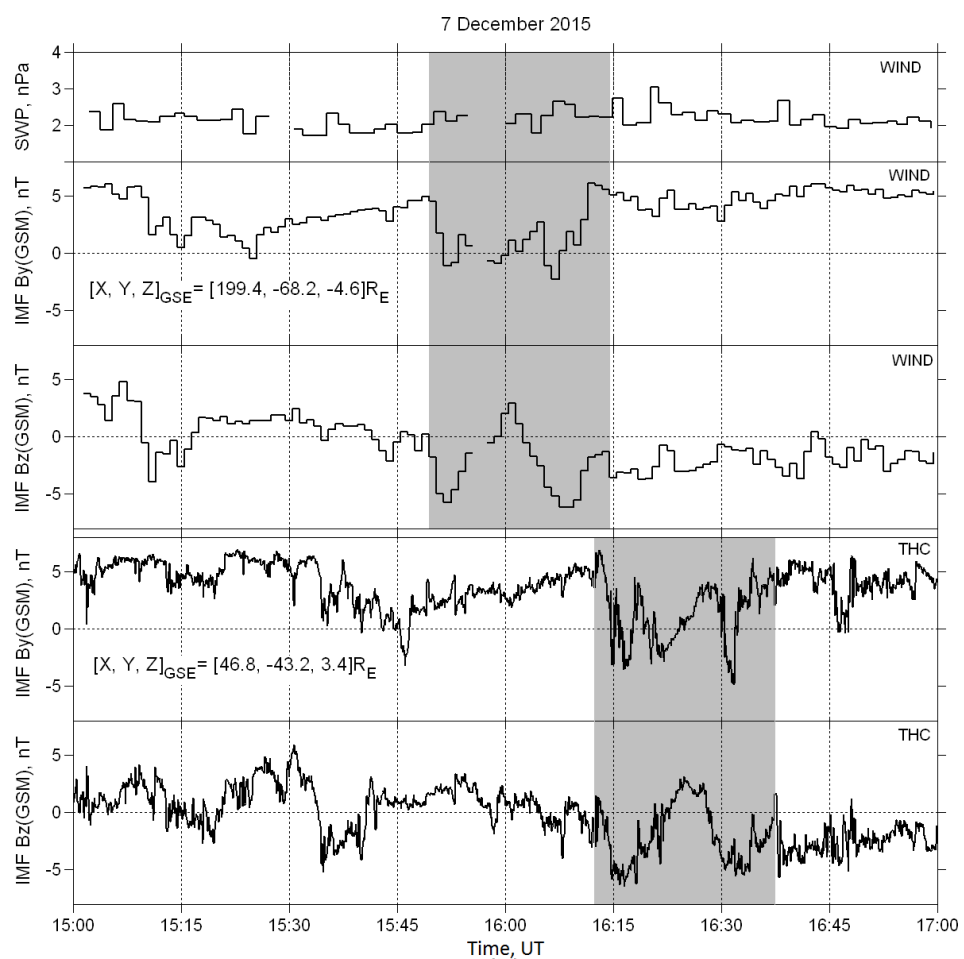

(b)

Figure 6. (a) Satellite positions in solar wind (WIND, THB, and THC) and in the magnetosphere (GEOTAIL). (b) Variations of the solar wind pressure and IMF $B z$ and $B y$ components. The two negative excursions of $B z$ on both of the satellites resembling the quasi-sinusoidal variation, with $\sim 15$ min periods, are highlighted in gray.

Assuming the nose of the bow shock at $14 R_{\mathrm{E}}$, we determine the propagation time from THC to the bow shock to be about $6 \mathrm{~min}$. The propagation time through the magnetosheath can be estimated as $14 \mathrm{~min}$ (Samsonov et al., 2017). Thus, the southward turning of IMF $B z$ could reach the magnetopause $20 \mathrm{~min}$ after registration onboard THC, and the ionospheric convection is expected to respond in $\sim 20 \mathrm{~min}$ after that (Hairson and Heelis, 1995).

The shaded areas in Fig. $6 \mathrm{~b}$ indicate the IMF $B z$ feature for which the shape and time correspond well to the features of ionospheric convection discussed above. Indeed, there are two southward IMF deflections at a 15 min separation, and the first deflection was detected at THC $40 \mathrm{~min}$ before the first flow enhancement in the polar cap (diagram $b$ in Fig. 4). In the moments between $16: 15$ and 16:30 UT when $B z$ at THB reached its maximal (negative) values, the IMF $B y$ component was near zero. This was favorable for the reconnection at the subsolar magnetopause. Importantly, the solar wind dynamic pressure does not show essential variations during the interval (top panel in Fig. 6b). We use this fact in Sect. 4.2 to exclude the influence of solar wind on the magnetic field variations near the equator.

\section{Features of the polar substorm onset}

\subsection{Auroral breakup}

As mentioned in Sect. 3.1, the auroral breakup started at about $T_{0}$ as the brightening and poleward displacement of the most equatorial auroral arc located slightly poleward of the northern coast of Scandinavia. The arc was too far away from the zenith of SOD for correct mapping. Due to the lack of optical observations between SOD and BAB, we can only speculate that the arc was between the westward and eastward electrojets and moved poleward together with them. The presumable location of the arc is shown by the black rectangle in Fig. 2b. Thus, for the first few minutes the auroral activity developed according to the traditional scenario.

The auroral situation changed at $\sim 17: 38$ UT when the amplitude of the negative $H$-component variation at $\mathrm{BJN}$ reached a maximum and a more rapid decrease in the $H$ component at LYR began (moment $T_{1}$ in Fig. 2a). Keograms in Fig. 2c show that after this moment the auroras within the field of view of BAB and SOD cameras moved in opposite directions. The auroras seen in SOD expanded almost $600 \mathrm{~km}$ equatorward, while the auroras observed in $\mathrm{BAB}$ shifted about $1000 \mathrm{~km}$ poleward. So that, by 17:42:37 UT the auroral configuration resembled the double-oval structure of $1600 \mathrm{~km}$ in width with bright poleward and equatorial edges 
and rather weak auroras inside. The next poleward excursion of auroras in $\mathrm{BAB}$, with less prominent equatorward shift in SOD, started at 17:49:32 UT and reached the northern horizon in the BAB camera field of view at 17:57:46UT. The interval between the maximal expansions of auroras to the north was about $15 \mathrm{~min}$, which is about the same as, first, the interval between the two negative bays in the geomagnetic $H$ component in SOD and KIL (Fig. 2a); second, the interval between the two negative excursions of IMF $B z$ component (Fig. 6b); and, third, the interval between the two bursts of antisunward flow in polar cap (Fig. 4).

Poleward displacement of the auroras started at about $T_{1}$ as the appearance of a new arc closer to the BAB zenith than preexisting auroras (Fig. 7a; image at 17:38:03 UT). The new arc included a series of bright patches. This feature is often referred to as "beading" (e.g., Keiling et al., 2012). At 17:38:27 UT, one of the patches gave rise to the auroral structure (indicated by the thin white arrow in Fig. 7a), which looks like an auroral torch (e.g., Tagirov, 1993). At this moment the structure was oriented approximately along the geomagnetic meridian and had a dimension of $170 \times 170 \mathrm{~km}$. Then the structure expanded to the west and north, transformed into the large-scale coiling structure (the term was suggested by Akasofu and Kimball, 1964), and broke up into bright strips, rays, patches, and vortices at 17:40 UT. The velocity of the structure's expansion in the first $10 \mathrm{~s}$ was about $5 \mathrm{~km} \mathrm{~s}^{-1}$ to the north and $10 \mathrm{~km} \mathrm{~s}^{-1}$ to the east. The auroral distribution before the collapse of the coiling structure is presented in Fig. $7 b$, together with the 2D configuration of the ionosperic equivalent currents.

Two vortices are seen in the current distribution. The center of the first (larger) vortex, indicating an upward FAC, is located between SOD and BJN. The second (smaller) vortex, indicating a downward FAC, is located poleward of LYR. A comparison with the auroral distribution shows that the center of the second vortex was poleward of the expanding coiling structure. At $\sim$ 17:39 UT, the structure reached the ESR in LYR. This moment is identified in the ESR data as a sharp increase in the E-region electron density (Fig. 5; top panel), which is a signature of auroral precipitation. At 1 min earlier, the ESR detected the ion temperature increase (Fig. 5; bottom panel), which indicates an enhanced electric field just poleward of the auroras.

To summarize, the vortices seen in the equivalent current are consistent with downward FAC at the poleward side of the coiling structure and upward FAC equatorward of it.

\subsection{Signatures of disruption of dawn-to-dusk plasma sheet current}

During the event, the GEOTAIL satellite was in the near equatorial magnetotail at $16 R_{\mathrm{E}}$ and $\sim$ 18:00 LT (Fig. 6a). The satellite footprint was calculated using the 4D Orbit Viewer (see Sect. 3.3). Taking into account the results of Safargaleev and Safargaleeva (2018) on the accuracy of distant satellite mapping, the latitude of the GEOTAIL footprint was estimated at $75 \pm 3^{\circ} \mathrm{N}$. The footprint is indicated in Fig. 7b (left panel) by a black square. At the moment indicated in the 2D diagram, the GEOTAIL position was mapped to the region of the westward electrojet.

Figure 8a shows the magnitude of the magnetic field at the GEOTAIL location. Before the onset at 17:30 UT, the horizontal $B x$ component drastically exceeded the $B z$ component, which means that the satellite was near the neutral current sheet (the cross-tail current is directed from dawn to dusk). After the time $T_{0}$, GEOTAIL was measuring the gradual decrease in the differential flux of energetic ions accompanied by the decrease in the absolute value of the $B x$ component (indicated by the gray shading), while the $B z$ component almost did not change. At this time, the westward electrojet where GEOTAIL was mapped was enhanced (Fig. 2b). These features of the magnetic filed, particle flux, and westward electrojet indicate a decrease or even local disruption in the dawn-to-dusk current in the vicinity of GEOTAIL. The local disruption of the cross-tail current causes a partial diversion of the current into the ionosphere and the formation of the substorm current wedge.

The bottom panel in Fig. 8b shows the variation in the $H$ magnetic field component at the low-latitude stations of $\mathrm{Al}$ ibag (ABG; $18.5^{\circ} \mathrm{N}, 72.9^{\circ} \mathrm{E}$; geomagnetic latitude $11.65^{\circ} \mathrm{N}$ ) located near midnight and at the dayside station San Juan $\left(\mathrm{SJG} ; 18.1^{\circ} \mathrm{N}, 293.8^{\circ} \mathrm{E}\right.$; geomagnetic latitude $28.79^{\circ} \mathrm{N}$ ). The increase in the $H$ component at low latitudes in all MLT sectors is traditionally connected with the enhancement of solar wind dynamic pressure, while decrease or disruption of the cross-tail magnetospheric current contributes to the Dst variation that is mainly on the nightside (Maltsev et al., 1996; Huang et al., 2004). Thus, the very different magnetic field behavior seen at ABG and SJG support the current disruption of the cross-tail current.

The spectrogram from GEOTAIL (Fig. 8a; top panel) shows that at 17:55 UT the flux and energy of protons start to increase. This was accompanied by the $B x$ reduction and $B z$ increase that indicates the dipolarization of magnetic field at the GEOTAIL location. After $5 \mathrm{~min}$, the increase in the flux stopped. Figure 2a shows a secondary, weaker onset at BJN at this moment, whereas at the higher latitudes (LYR) the recovery phase started. This is different from the case described by Baker et al. (1996), who observed that the recovery phase started in the auroral zone and a new negative bay started at higher latitudes (i.e., on opposite to our case). Assuming that the reappearance of the energetic ions in Fig. 8a indicates rapid plasma sheet thickening (Baker et al., 1996), one can suppose that the dipolarization and second onset and/or intensification were due to the neutral line formation. 
7 December 2015
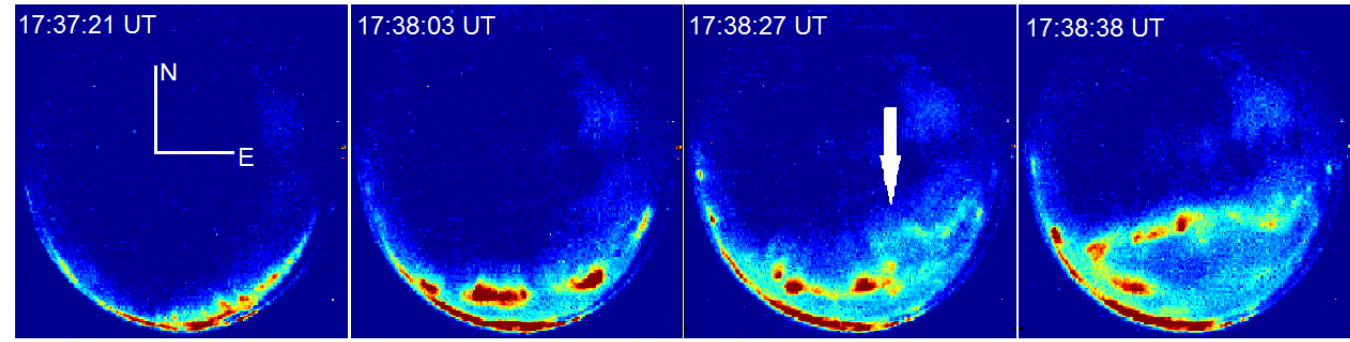

(a)

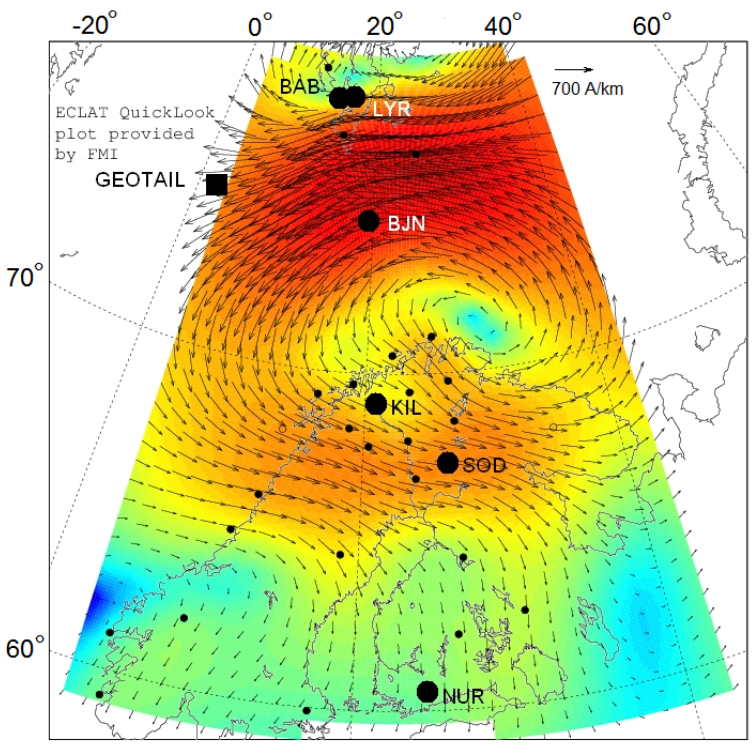

17:38:40 UT
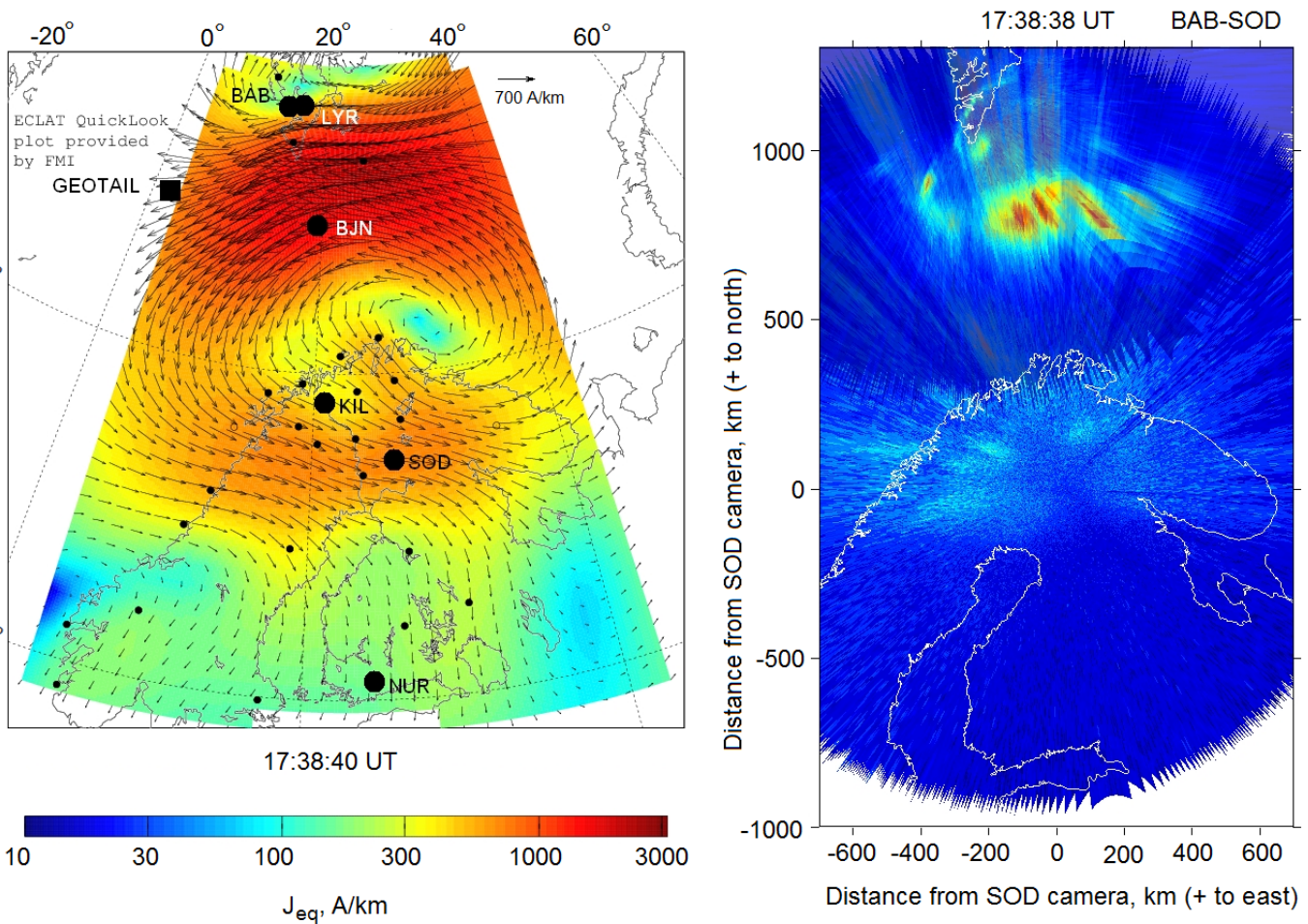

(b)

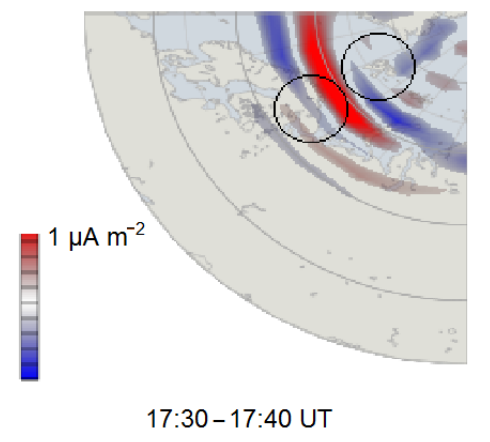

(c)

Figure 7. (a) Sequence of BAB all-sky images showing the series of bright patches along the enhancing arc and development of the torch-like structure from one of them. The left panel (b) shows a snapshot of a 2D-equivalent current. The right panel (b) shows the mapped SOD and BAB all-sky images that indicate the shape of auroras. The black square and circles indicate the position of the GEOTAIL footprint and IMAGE observatories, respectively. (c) The distribution of the FAC inferred from the AMPERE data. Upward currents are indicated in red and downward currents in blue. Circles indicate the field of view of the all-sky cameras. 


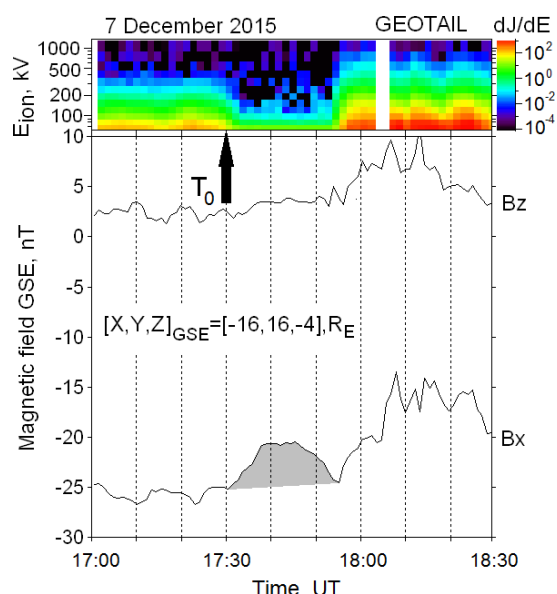

(a)

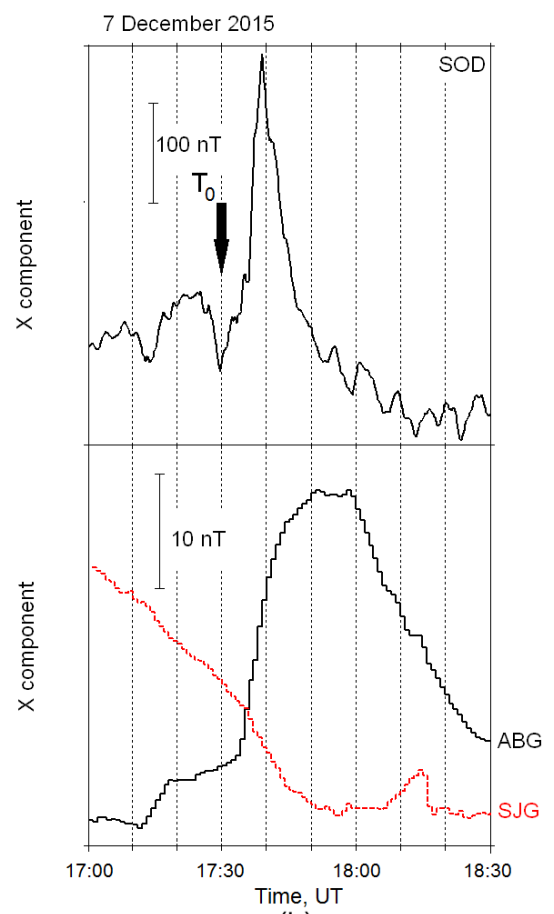

(b)

Figure 8. (a) Spectrogram showing the intensity variations of the differential ion flux (top panel) and magnetic field at GEOTAIL (bottom panel). (b) Variations of the geomagnetic X component at subauroral (SOD) and low-latitude (Alibag - ABG; San Juan - SJG) stations. The black arrow indicates the polar substorm onset time, $T_{0}$, and the dayside variation is indicated in red.

\section{Discussion}

\subsection{Summary of prebreakup observations}

We identify the substorm onset time, $T_{0}$, as the beginning of the negative bay at the high-latitude station BJN. In addition, at this time the intensification and poleward displacement of the westward electrojet began (Fig. 2b). The auroral breakup started at around $T_{0}$ as $1 \mathrm{~min}$ of fading and then brightening of the preexisting auroral arc at about $400 \mathrm{~km}$ north of Sodankylä. The DMSP data of the precipitating particles show that, $20 \mathrm{~min}$ before $T_{0}$, the poleward edge of the auroral oval (b5e boundary in Fig. 3b) was near BJN. For this reason, and following Kleimenova et al. (2012), we attributed the event to the subclass of polar substorms.

The polar substorm was preceded by two rather weaker $(\sim 80 \mathrm{nT})$ negative bays, recorded by IMAGE magnetometers deep inside the auroral oval, and following each other through a $15 \mathrm{~min}$ interval. The bays were accompanied by the brightening of the auroras near the north edge of the SOD camera field of view and their poleward displacement. Preonset phenomena with the same time separation were found in the polar cap plasma flow and IMF variations.

The search for preonset phenomena in the ionospheric convection and in the solar wind was based, first, on the time response of the magnetosphere to solar wind changes and, second, on the observation of the 15 min separation. The search results are shown in Figs. 6 and $4 \mathrm{~b}$ and represent two negative excursions in the IMF $B z$ component and two bursts of the antisunward ionospheric plasma flow across the polar cap, respectively. Earlier Russell (2000) discussed the possible role in the classical substorm development of a single negative $B z$ variation (i.e., when the northward IMF turns southward and then northward again). However, Safargaleev et al. (2018) proposed that the polar substorm might be triggered by a quasi-sinusoidal variation in $B z$.

The hypothesis of dayside reconnection is supported by the density patch observed by ESR in the polar cap at about $T_{0}$ (see Fig. 5). Accordingly to Lockwood and Carlson (1992), the patch may be associated with the reconnected flux tube moving from cusp to the lobe, and the plasma flow from polar cap to the auroral oval during the substorm preonset phase was observed by Mishin et al. (2017). The patch in the ESR data was associated with a southward displacement of the poleward boundary of the westward electrojet (Fig. 2b). Taking into account that BJN and, hence, the westward electrojet were near the polar cap, the southward shift of the electrojet boundary indicates the swelling of magnetotail lobe in the course of energy storage. The swelling of both lobes leads to plasma sheet thinning, which makes it instable due to the highly stressed magnetic configuration.

Optical observations in the polar cap near the boundary of the auroral oval do not reveal any aurora which might be attributed to the electron density patch in the ESR data. The lack of optical data over BJN (see Fig. 1) do not allow us to conclude whether the patch was associated with poleward boundary intensifications (PBIs).

\subsection{Summary of breakup observations}

The auroral breakup at the initial stage proceeded as the brightening and poleward displacement of one of the preexisting arcs located deep inside the auroral oval, presumably between the westward and eastward electrojets near the pole- 
ward edge of diffuse auroras seen from SOD. After that, the smaller-scale (compared to the WTS or auroral bulge) structure originated from the bright spot at the southern horizon of $\mathrm{BAB}$ and expanded westward and poleward at the velocity of 10 and $5 \mathrm{~km} \mathrm{~s}^{-1}$, respectively, which is close to a typical velocity of the WTS expansion. During the first few seconds the structure resembled the auroral torch, but before the collapse it had a coiling shape. Akasofu (1977) showed that WTS develops typically at magnetic latitudes between 65 and $70^{\circ}$, whereas in the present case the torch-like structure appeared higher than $70^{\circ}$ N GLAT. Sergeev and Yahnin (1979) observed that the substorm bulge originates equatorward of the open-closed field line region and then expands up to, but not beyond, a more poleward arc system which, perhaps, delineates the open-closed field line boundary. In the present case no auroras were seen poleward of the torch formation near the poleward boundary of the auroral oval (b5e boundary in Fig. 3b; Sect. 3.1). Hence, the generation mechanisms for torch and WTS may be different.

The moment of generation of the torch-like structure was preceded by the formation of series patches along the arc (beading structure). This structure was regarded by Keiling et al. (2012) as a signature of the interchange instability on the outer boundary of the plasma sheet, which might be responsible for the torch appearance. If the $b 5 e$ boundary corresponds to the ionospheric projection of the outer edge of the plasma sheet, the interchange hypothesis looks reasonable. Earlier, Rezhenov (1995) suggested this kind instability to explain the generation of the transpolar arc.

The distribution of field-aligned currents in the vicinity of the coiling structure inferred from the AMPERE measurements (Fig. 7c) shows a downward and upward FAC poleand equatorward of the structure, respectively, which corresponds to the statistical results of Iijima and Potemra (1978) showing three current sheets (two downward and one upward between them) in the premidnight sector. Note that indeed the polar substorms are preferentially observed in this MLT sector (Kleimenova et al., 2012). Classical substorms start at lower latitudes where the current distribution is opposed to that of high latitudes; i.e., the upward current is north of the stable arc and downward current is equatorward (Aikio at al., 2002). Thus, a key difference between the polar and classical substorms may be in the position of the breaking auroras relative to the large-scale down- and upward currents.

Typically, auroral arcs occur in the regions of large-scale upward field-aligned currents associated with the downward fluxes of electrons. However, Kozlovsky et al. (2005) have shown that at magnetospheric plasma boundaries the KelvinHelmholtz (K-H) instability may lead to generation of auroral wavelike forms, even in the region of a large-scale downward FAC. At the initial stage of instability development, such structures look like a series of auroral spots resembling the beading structure. Thus, the $\mathrm{K}-\mathrm{H}$ instability may be responsible for the generation of both the torch-like and coiling auroras. Note also that such configurations of the field-

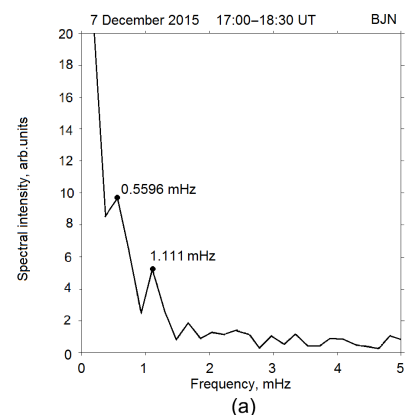

(a)

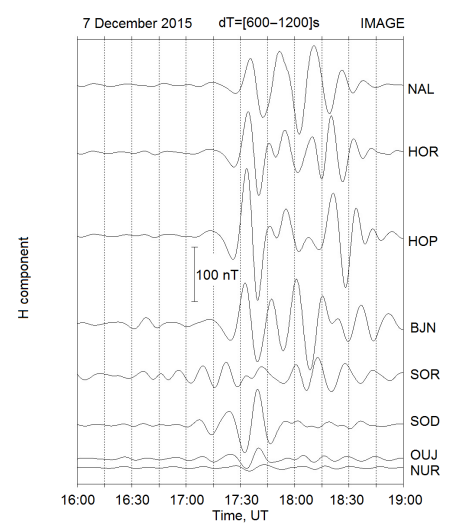

(b)

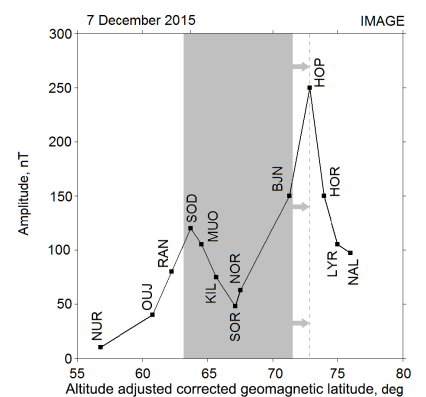

(c)

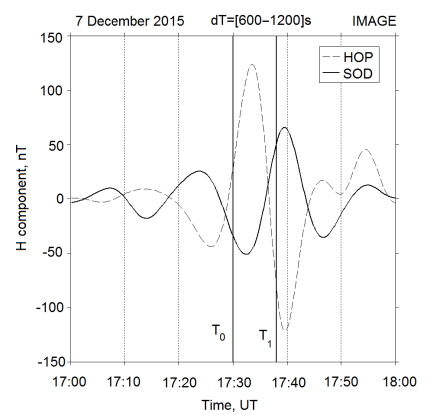

(d)

Figure 9. Wave portrait of polar substorms: (a) power spectrum of variations in $H$ component at $\mathrm{BJN}$, where the onset begins (see Fig. 2a); (b) variations of $H$ component in a band of $15 \pm 5 \mathrm{~min}$ at IMAGE stations located along the meridian (the presumable width of the auroral oval is indicated in gray); (c) latitudinal (alongmeridian) distribution of pulsation intensity; and (d) out-of-phase variations at the SOD and HOP stations, where the latitudinal distribution of pulsation intensity has its maxima. Open arrows show the time of the enhancement of prebreakup arcs. $T_{0}$ and $T_{1}$ are the times of onset and torch formation, respectively. 
aligned currents in vicinity of the breakup auroras hinders the development of the interchange instability.

The set of satellite and ground observations (Sect. 4.2) allows us to interpret the gap in the flux of hot ions at the location of GEOTAIL, which started at the moment $T_{0}$, as a decrease or local disruption in the dawn-to-dusk current in plasma sheet and its partial diversion into the ionosphere in the course of substorm current wedge formation. The signatures of dipolarization were observed on GEOTAIL 25 min later, and we associate the dipolarization with reconnection in the magnetotail and the second onset and/or intensification at BJN. We note the unexpected large positive variation in the $H$ component at the nightside equatorial station (Fig. 8b), which we explain by the weakening of currents in the magnetotail (see also Huang et al., 2004).

Finally, we emphasize the $15 \mathrm{~min}$ time separation in the aurora development. The keograms in Fig. 2c show that after moment $T_{1}$ auroras over BAB and SOD moved in opposite directions, giving the impression of the periodical swelling of magnetotail plasma sheet. We think that the $15 \mathrm{~min}$ periodicity in the preonset and breakup processes is the most intriguing finding and deserves a more detailed discussion. We remind the reader that by the 15 min periodicity of a parameter we mean two its changes, following one after the other, with an interval of $15 \mathrm{~min}$.

\subsection{Periodicity in the processes prior to and during the polar substorm onset}

The estimation of the period depends on a number of factors, such as data resolution; subjectivism in the choice of the way of estimation (e.g., when we estimated repetition period of convection enhancements in polar cap and auroral activity over SOD); and uncertainty in the definition of the moment of $\mathrm{max} / \mathrm{min}$ variations (e.g., when we estimated period as interval between two consecutive maximal declinations in $H$ and $B z$ components), etc. So, it really is a period of $15 \pm 2 \mathrm{~min}$, i.e., close to the $15 \mathrm{~min}$ period. Thus, the term " 15 min periodicity" is general and does not mean an exact value.

The period of about a $15 \mathrm{~min}$ (frequency $1 \mathrm{mHz}$ ) corresponds to the irregular pulsations, continuous, and long (IPCL) or Ps6 geomagnetic pulsations. The former are a typical feature of the dayside cusp (e.g., Troitskaya, 1985). The latter are a subclass of the Pi3 pulsations (Saito, 1978), which are detected in the $Y$ component and associated with the omega auroras (e.g., Jorgensen et al., 1999). In addition, signatures of nearly $15 \mathrm{~min}$ magnetosphere oscillations were found in the modulation of ultra low-frequency (ULF) activity (Safargaleev et al., 2002), the DOppler Pulsation Experiment (DOPE) sounder radar data (Wright and Yeoman, 1999), and the GPS total electron content (TEC) variations (Watson et al., 2015). Thus, the role of nearly $15 \mathrm{~min}$ oscillations is not limited only to substorms but may be attributed to wider range of magnetospheric processes.
First, the 15 min periodicity as two negative excursions was detected in the variations of IMF $B z$ (Fig. 6b). Then, there were two consecutive enhancements of the antisunward plasma flow in the polar cap (Fig. 4). The time delay between the flow enhancements and the IMF $B z$ variations suggests that the former was a consequence of the latter. A similar repetition period was found in the two negative bays of about $80 \mathrm{nT}$ in the $H$ component and the accompanying aurora intensifications (arc 1 and arc 2) inside the auroral zone (Fig. 2a). The bays followed the plasma flow enhancements, and the time delay indicated their relation to the IMF $B z$ variations.

The second feature was found in the latitudinal distribution of the intensity of $15 \mathrm{~min}$ geomagnetic pulsations. Figure 9 demonstrates a wave portrait of the polar substorm. Power spectrum of variations in $H$ component at $\mathrm{BJN}$, where the substorm begins, has two peaks. The first peak corresponds to a period of about $30 \mathrm{~min}$ that is close to the interval between two substorm activations at BJN magnetogram (Fig. 2a). The second peak corresponds to a period of $15 \mathrm{~min}$. The close period we observed in abovementioned disturbances in IMF $B z$, plasma flow in polar cap and prebreakup variations in the $H$ component at KIL and SOD. Variations of the $H$ component in the frequency band $0.8-1.7 \mathrm{mHz}$ (period $\Delta T=15 \pm 5 \mathrm{~min}$ ) for some IMAGE stations are shown in Fig. 9b. Two maxima at SOD and at Hopen Island (HOP; geomagnetic latitude $72.85^{\circ} \mathrm{N}$ ) are seen in the latitudinal distribution of the pulsation amplitude in Fig. 9c, where the gray shading shows position of the auroral oval $20 \mathrm{~min}$ before the onset, as it was estimated in Sect. 3.1. The maxima of both were at $\sim 17: 34$ UT. By this time, the expanding auroras and the westward electrojet might shift noticeably to the north (gray arrows in Fig. 2b), so that the poleward boundary of the auroral oval occurred closer to HOP than to BJN, compared to that which occurred during the DMSP flight. A new presumable location of the footprint of the outer edge of the plasma sheet is indicated by the gray dashed line. The keogram in Fig. 2a indicates that the equatorial edge of the auroral oval was southward of SOD at this time.

For a pure Alfvén wave, the period of oscillations is defined by the propagating time of the wave between conjugated ionospheres and should depend on the length of the magnetic field line (i.e., on the latitude); however, we do not observe such a dependence in the present case. Although the latitudinal separation of the peaks is very large (about $10^{\circ}$ ), the pulsations have almost the same period along the meridian (Fig. 9b). Moreover, the magnetosphere is inhomogeneous along the meridian and includes at least three different areas, namely lobes, plasma sheet, and a gap between the plasma sheet and plasmasphere. This observation may be explained by the coupling of the Alfvén and compressional modes excited from the outside by two negative excursions of IMF $B z$.

The third feature is the out-of-phase magnetic variations at the SOD and HOP stations where pulsations have local max- 
ima. Figure 9d shows at least five events of phase shifts by $180^{\circ}$ at the interval of about $7-8 \mathrm{~min}$ (half period of pulsations). Two open arrows indicate the preonset enhancement of arc 1 and $\operatorname{arc} 2$. The moment $T_{0}$ corresponds to the substorm onset (i.e., the beginning of negative declination at BJN in Fig. 2a), which is also accompanied by the brightening of the preexisting aurora arc over SOD. The moment $T_{1}$ corresponds to the beginning of the auroral torch development in Fig. 7a, which was preceded by the appearance of a new arc in BAB.

Although the out-of-phase oscillations of two neighboring L shells is a signature of the field line resonance (FLR), the present case is essentially different from FLR. Namely, the 15 min pulsations are detected in the latitudinal range of $\sim 20^{\circ}$ at least, whereas typical FLR are observed in a narrow latitudinal range of the order of $2^{\circ}$ (Walker et al., 1979). Then, the period of FLR is typically less than $10 \mathrm{~min}$. Note that the frequency of some pulsations may be defined not only by the internal structure or size of the magnetosphere but also by the frequency of some external driver (e.g., solar wind), and FLR may be excited from the outside (e.g., Walker, 2005).

Following Sarafopoulos (2005), we nominate the out-ofphase oscillations in Fig. 9d as being the pseudo-FLR event. Following Lyatsky et al. (1999), we suppose that the out-ofphase variations of two neighboring $L$ shells (which are the inner and outer boundaries of the plasma sheet in our case) lead to the field-aligned current between the shells, which can be responsible for the intensification of the preexisting arc 1 and arc 2, and the breakup arcs at the moments $T_{0}$ and $T_{1}$.

\subsection{Generation mechanism of polar substorm}

In general, the substorm growth phase occurs as a result of an enhanced dayside reconnection rate, usually initiated by a southward turning of the IMF, concurrent with a comparably small nightside reconnection rate (Milan et al., 2007). However, a number of models of substorm triggering based on observations have been suggested (see Rae et al., 2014, and references therein).

The ground data show that the considered event evolved in four stages, namely (1) two enhancements of antisolar convection in the polar cap, (2) two weak negative deviations in the magnetic field $H$ component inside the auroral oval that were accompanied by aurora enhancement and looked like the pseudobreakups, (3) a polar substorm as a more intensive negative bay at the poleward edge of auroral oval and, finally, (4) an intensification (one more onset) approximately at the same position. We believe that these stages were due to different reasons and played different roles in the substorm development.

The convection enhancements were caused by negative deviations of the IMF $B z$ component (e.g., Ruohoniemy and Greenwald, 1998) and lead to the increase in magnetic en- ergy in the lobes of the magnetosphere. Two weak variations in the $H$ component at KIL and SOD might be the ground signature of global oscillations of the magnetospheric cavity (see Fig. 9). The oscillations might be excited by the periodic erosion of the dayside magnetopause in the course of periodic reconnection (e.g., Agapitov et al., 2009). The conclusion regarding periodic reconnection is based on periodic enhancement of plasma velocity in the polar cap (see Sect. 3.2).

Amplitude distribution of the oscillations has two maxima in the vicinity of equatorial and poleward boundaries of the auroral oval where the oscillations occur in the out-ofphase mode. We consider these out-of-phase oscillations as, at least, a reason for the auroral arc intensification via the pseudo-field-line resonance excitation.

The set of satellite and ground data fit to the near-tail current disruption scenario of the polar substorm. However, the data set does not allow us to specify a reason for the disruption. We suppose that this might happen due to pseudo-FLR. The role of the typical FLR event (i.e., out-of-phase variations at two neighboring $\mathrm{L}$ shells) in the substorm initiation was discussed in many papers (e.g., Samson et al., 1992; Rae et al., 2014 and references therein). The question of whether the out-of-phase variations at the inner and outer boundaries of the plasma sheet can be launched from the outside and lead to the same effects as the FLR is the subject for a separate theoretical investigation that is beyond the scope of this study.

Finally, the fourth stage of the polar substorm development, i.e., second onset or intensification, is associated with the magnetotail reconnection.

\section{Conclusions}

We present the comprehensive description of the moderate polar substorm (the term was suggested by Kleymenova et al., 2012), focusing on the multi-instrumental study of preonset events in the solar wind, ionosphere, and on the ground. The onset took place at premidnight near the poleward boundary of the auroral oval that is not typical for classical substorms. We have shown that the auroral breakup developed between two field-aligned currents with a downward current poleward breaking the auroras and an upward current south of them. This morphological feature distinguishes the polar substorm from classical ones.

The onset was preceded by two negative excursions of the IMF $B z$ component, with a time separation $\sim 15 \mathrm{~min}$. These variations caused two bursts of reconnection at the magnetopause. Two enhancements of the antisunward convection in the polar cap and appearance of the ionospheric patch near the polar cap boundary support the reconnection hypothesis. On the one hand, the reconnection leads to the increase in the magnetic energy in the lobes and the corresponding thinning of the plasma sheet that creates favorable conditions for a substorm initiation. On the other hand, the repeated erosion 
of the magnetopause excites the global 15 min oscillation of the magnetospheric cavity. The oscillations are observed in the auroral zone. The period of the oscillations does not depend on the latitude, which means that the pulsations represent forced oscillations of the magnetosphere cavity. The latitudinal distribution of the oscillations' intensity has maxima near the equatorial and poleward boundaries of the auroral oval where the oscillations occur in the out-of-phase regime resembling the field line resonance.

The onset was accompanied by the disruption of the dawnto-dusk current in the plasma sheet around $(x, y) \sim(-16$, 16) $R_{\mathrm{E}}$ and the current wedge formation. We conclude this from the data of the GEOTAIL satellite showing the reduction in the absolute value of the $B x$ component (e.g., Lui et al., 1992) and the dropout of high-energy electrons, enhancement of the westward electrojet, and the large positive variation in $H$ component at low latitudes. According to Lui (1996), current disruption activity is limited both radially and azimuthally to $-1 R_{\mathrm{E}}$. Since the GEOTAIL detected the changes in $B x$ and the electron flux and was magnetically conjugated with changing electrojet, we suggest that current decrease and/or disruption took place in the satellite's vicinity.

We think that the onset might be initiated by the out-ofphase oscillations in the same way that field line resonance does (e.g., Rae et al., 2014).

Data availability. The ASC data are archived in the Magnetometers - Ionospheric Radars - All-sky Cameras Large Experiment (MIRACLE) database, which is maintained under the leadership of the Finnish Meteorological Institute: https://space.fmi.fi/ MIRACLE/ASC/, last access: 16 March 2019. Data requests should be sent to Kirsti Kauristie (kirsti.kauristie@fmi.fi). BAB optical data are not publicly accessible for technical reasons and can be provided upon request.

Author contributions. VVS provided the optical data of the Polar Geophysical Institute (PGI) all-sky camera in Barentsburg, and AEK provided the optical data of the SOD all-sky camera in Sodankylä. VMM processed the BAB optical data and mapped auroras and the DMSP pass. VVS prepared the paper with contributions from all coauthors.

Competing interests. The authors declare that they have no conflict of interest.

Acknowledgements. We are grateful to FMI/GEO and other institutes that maintain the IMAGE magnetometer network (http: //space.fmi.fi/image/www/index.php?, last access: 16 March 2020). We acknowledge Vassilis Angelopoulos at UCB, NASA (grant no. NAS5-02099) for the data from THEMIS, Susumu Kokubun at the Solar-Terrestrial Environment Laboratory (STELab) of Nagoya
University, Japan, Donald J. Williams at APL/JHU for the data from GEOTAIL, Adam Szabo and Keith W. Ogilvie at NASA/GSFC for data from WIND, and CDAWeb for allowing us to use all these data (https://cdaweb.sci.gsfc.nasa.gov/index.html/, last access: 14 May 2019). The DMSP particle detectors were designed by Dave A. Hardy, Fred J. Rich, and their colleagues at Air Force Research Laboratory (AFRL) at the Hanscom Air Force Base in Boston. The U.S. Air Force has publicly released this data. Most of it was obtained through WDCA for Solar Terrestrial Physics (NOAA) in Boulder, Colorado USA, with generous supplements from AFRL (http://sd-www.jhuapl.edu/Aurora/spectrogram/index. html). We thank Dave A. Hardy, Fred J. Rich, and Patrick T. Newell for its use. The Kp and Dst indices are from the Kyoto World Data Centre for Geomagnetism in Kyoto, Japan (http://wdc.kugi. kyoto-u.ac.jp/). Some results rely on the data collected at the ABG and SJG observatories. We thank IIG, India, and USGS, USA, for supporting their operation and for promoting high standards of magnetic observatory practice (http://www.intermagnet.org/index-eng. $\operatorname{php}\{\#\})$. The authors acknowledge the use of the SuperDARN data. SuperDARN is a collection of radars funded by national scientific funding agencies from Australia, Canada, China, France, Italy, Japan, Norway, South Africa, UK, and USA. SuperDARN data are available from the SuperDARN website hosted by Virginia Tech (http://vt.superdarn.org). The authors appreciate the EISCAT Scientific Association for making the data observed by the ESR freely accessible on the Madrigal website (PI is Ingemar Häggström https://www.eiscat.se/schedule/schedule.cgi). We thank the AMPERE team and the AMPERE Science Centre for providing the Iridium-derived data products at http://ampere.jhuapl.edu/index. html. BAB and SOD all-sky cameras are operated by PGI, Russia (PI Roldugin), and SGO, Finland. We thank Natalya N. Safargaleeva (PGI) for the BAB optical data selection. Vladimir V. Safargaleev acknowledges support from the Academy of Finland (grant no. 316991).

Financial support. The research of Vladimir V. Safargaleev was supported by the Academy of Finland (grant no. 316991).

Review statement. This paper was edited by Minna Palmroth and reviewed by three anonymous referees.

\section{References}

Agapitov, O., Glassmeier, K.-H., Plaschke, F., Auster, H.-U., Constantinescu, D., Angelopoulos, V., Magnes, W., Nakamura, R., Carlson, Ch. W., Frey, S., and McFadden J. P.: Surface waves and field line resonances: A THEMIS case study, J. Geophys. Res., 114, A00C27, https://doi.org/10.1029/2008JA013553, 2009.

Aikio, A. T., Lakkala, T., Kozlovsky, A., and Williams, P. J. S.: Current systems of stable drifting auroral arcs in the evening sector, J. Geophys. Res., 107, 1424, https://doi.org/10.1029/2001JA009172, 2002.

Akasofu, S.-I.: Physics of Magnetospheric Substorms, Astrophysics and Space Science Library, Vol. 47, edited by: Reidel, D., Hingham, Mass., 619 pp., 1977. 
Akasofu, S.-I. and Kimball, D. S.: The dynamics of the aurora - I: Instability of aurora, J. Atmos. Terr. Phys., 26, 205-206, https://doi.org/10.1016/0021-9169(64)90147-3, 1964.

Amm, O. and Viljanen, A.: Ionospheric disturbance magnetic field continuation from the ground to the ionosphere using spherical elementary current systems, Earth Planet. Space, 51, 431-440, https://doi.org/10.1186/BF03352247, 1999.

Amm. O., Engebretson, M. J., Hughes, T., Newitt, L., Viljanen, A., and Watermann, J.: A traveling convection vortex event study: Instantaneous ionospheric equivalent currents, estimation of fieldaligned currents, and the role of induced currents, J. Geophys. Res., 107, 1334, https://doi.org/10.1029/2002JA009472, 2002.

Baker, D., Pulkkinen, T., Angelopoulos, V., Baumjohann, W., and McPherron, R.: Neutral line model of substorms: Past results and present view, J. Geophys. Res., 101, 12975-13010, https://doi.org/10.1029/95JA03753, 1996.

Baker, D. N., Pulkkinen, T. I., McPherron, R. L., Craven, J. D., Frank, L. A., Elphinstone, R. D., Murphree, J. S., Fennell, J. F., Lopez, R. E., and Nagai, T.: CDAW 9 analysis of magnetospheric events on May 3, 1986, Event C, J. Geophys. Res., 98, 3815-3834, https://doi.org/10.1029/92JA02475, 1993.

Bargatze, L. F., Ogino, T., McPherron, R. L., and Walker, R. J.: Solar wind magnetic field control of magnetospheric response delay and expansion phase onset timing, J. Geophys. Res., 104, 14583-14600, https://doi.org/10.1029/1999JA900013, 1999.

Baumjohann, W., Pellinen, R., Opgenoorth, H. J., and Nielsen, E.: Joint two-dimensional observations of ground magnetic ionospheric electric fields associated with auroral zone currents: Current systems associated with local auroral break-ups, Planet. Space Sci., 29, 431-447, https://doi.org/10.1016/00320633(81)90087-8, 1981.

Brito, T. V. and Morley, S. K.: Improving Empirical Magnetic Field Models by Fitting to In Situ Data Using an Optimized Parameter Approach, J. Space Weather., 15, 1628-1648, https://doi.org/10.1002/2017SW001702, 2017.

Buchau, J., Reinisch, B. W., Weber, E. J., and Moore. J. G.: Structure and dynamics of the winter polar cap $F$ region, Radio. Sci., 18, 995-1010, https://doi.org/10.1029/RS018i006p00995, 1983.

Chisham, G., Lester, M., Milan, S. E., Freeman, M. P., Bristow, W. A., Grocott, A., McWilliams, K. A., Ruohoniemi, J. M., Yeoman, T. K., Dyson, P. L., Greenwald, R. A., Kikuchi, T., Pinnock, M., Rash, J. P. S., Sato, N., Sofko, G. J., Villain, J.P., and Walker, A. D. M.: A decade of the Super Dual Auroral Radar Network (SuperDARN): Scientific achievements, new techniques and future directions, Surv. Geophys., 28, 33-109, https://doi.org/10.1007/s10712-007-9017-8, 2007.

Finnish Meteorological Institute: ASC data, available at: https: //space.fmi.fi/MIRACLE/ASC/, last access: 16 March 2019.

Golovchanskaya, I. V., Kornilov, I. A., and Kornilova, T. A.: Eastwest type precursor activity prior to the auroral onset: groundbased and THEMIS observations, J. Geophys. Res., 120, 11091123, https://doi.org/10.1002/2014JA020081, 2015.

Greenwald, R. A., Baker, K. B., Dudeney, J. R., Pinnock, M., Jones, T. B., Thomas, E. C., Villain, J.-P., Cerisier, J.-C., Senior, C., Hanuise, C., Hunsucker, R. D., Sofko, G., Koehler, J., Nielsen, E., Pellinen, R., Walker, A. D. M., Sato, N., and Yamagishi, Y.: DARN/SuperDARN: A global view of high-latitude convection, J. Space Sci. Rev., 71, 761-796, https://doi.org/10.1007/BF00751350, 1995.
Hairston, M. R. and Heelis, R. A.: Response time of the polar ionospheric convection pattern to changes in the north-south direction of the IMF, J. Geophys. Res. Lett., 22, 631-634, https://doi.org/10.1029/94GL03385, 1995.

Huang, C.-S., Foster, J. C., Goncharenko, L. P., Reeves, G. D., Chau, J. L., Yumoto, K., and Kitamura, K.: Variations of low-latitude geomagnetic fields and Dst index caused by magnetospheric substorms, J. Geophys. Res., 109, A05219, https://doi.org/10.1029/2003JA010334, 2004.

Iijima, T. and Potemra, T. A.: Large-scale characteristics of fieldaligned currents associated with substorms, J. Geophys. Res., 83, 599-615, https://doi.org/10.1029/JA083iA02p00599, 1978.

Jorgensen, A. M., Spence, H. E., Huges, T. J., and McDiarmid, D.: A study of omega bands and Ps6 pulsations on the ground, at low altitude and at geostationary orbit, J. Geophys. Res., 104, 14705-14715, https://doi.org/10.1029/1998JA900100, 1999.

Keiling, A., Shiokawa K., Uritsky, V., Sergeev, V., Zesta, E., Kepko, L., and Østgaard, N.: Auroral signatures of the dynamic plasma sheet, in: Auroral Phenomenology and Magnetospheric Processes: Earth And Other Planets, edited by: Keiling, A., Donovan, E., Bagenal, F., and Karlsson, T., American Geophysical Union, Washington, D.C., Geophys. Monogr, 197, 317-336, https://doi.org/10.1029/2012GM001231, 2012.

Kleimenova, N. G., Antonova, E. E., Kozyreva, O. V., Malysheva, L. M., Kornilova, T. A., and Kornilov, I. A.: Wave structure of magnetic substorms at high latitudes, Geomagn. Aeron., 52, 746-754, https://doi.org/10.1134/S0016793212060059, 2012.

Koskinen, H. E. J., Lopez, R. E., Pellinen, R. J., Pulkkinen, T. I., Baker, D. N., and Bosinger, T.: Pseudobreakups and substorm growth phase in the ionosphere and magnetosphere, J. Geophys. Res., 98, 5801-5813, https://doi.org/10.1029/92JA02482, 1993.

Kozlovsky, A., Nilsson, H., Sergienko, T., Aikio, A. T., Safargaleev, V., Turunen, T., and Kauristie, K.: On the field-aligned currents in the vicinity of prenoon auroral arcs, Geophys. Res. Lett., 32, L18104, https://doi.org/10.1029/2005GL023120, 2005.

Liou, K., Sotirelis, T., and Gjerloev, J.: Statistical study of polar negative magnetic bays driven by interplanetary fastmode shocks, J. Geophys. Res.-Space, 122, 7463-7472, https://doi.org/10.1002/2017JA024465, 2017.

Lockwood, M. and Carlson, H. C.: Production of polar cap electron density patches by transient magnetopause reconnection, Geophys. Res. Lett., 19, 1731-1734, https://doi.org/10.1029/92GL01993, 1992.

Lui, A.: Current disruption in the Earth's magnetosphere: Observations and models, J. Geophys. Res., 101, 13067-13088, https://doi.org/10.1029/96JA00079, 1996.

Lui, A. T. Y.: Current disruption in the Earth's magnetosphere: Observations and models, J. Geophys. Res., 101, 13067-13088, https://doi.org/10.1029/96JA00079, 1996.

Lui, A. T. Y., Lopez, R. E., Anderson, B. J., Takahashi, K., Zanetti, L. J., McEntire, R. W., Potemra, T. A., Klumpar, D. M., Greene, E. M., and Strangeway R.: Current disruptions in the nearEarth neutral sheet region, J. Geophys. Res., 97, 1461-1480, https://doi.org/10.1029/91JA02401, 1992.

Lyatsky, W., Elphinstone, R. D., Pao, Q., and Cogger, L. L.: Field line resonance interference model for multiple auroral arc generation, J. Geophys. Res., 104, 263-268, https://doi.org/10.1029/1998JA900027, 1999. 
Lyons, L. R., Nagai, T., Blanchard, G. T., Samson, J. C., Yamamoto, T., Mukai, T., Nishida, A., and Kokubun, S.: Association between Geotail plasma flows and auroral poleward boundary intensifications observed by CANOPUS photometers, J. Geophys. Res., 104, 4485-4500, https://doi.org/10.1029/1998JA900140, 1999.

Maltsev ,Y. P., Arykov, A. A., Belova, E. G., Gvozdevsky, B. B., and Safargaleev, V. V.: Magnetic flux redistribution in the storm time magnetosphere, J. Geophys. Res., 101, 7697-7704, https://doi.org/10.1029/95JA03709, 1996.

Milan, S. E., Provan, G., and Hubert, B.: Magnetic flux transport in the Dungey cycle: A survey of dayside and nightside reconnection rates, J. Geophys. Res., 112, A01209, https://doi.org/10.1029/2006JA011642, 2007.

Mishin, V. M., Saifudinova, T., Bazarzhapov, A., Russell, C. T., Baumjohann, W., Nakamura, R., and Kubyshkina, M.: Two distinct substorm onsets, J. Geophys. Res., 106, 13105-13118, https://doi.org/10.1029/2000JA900152, 2001.

Mishin, V. M., Mishin, V. V., Lunyushkin, S. B., Wang, J. Y., and Moiseev, A. V.: 27 August 2001 substorm: Preonset phenomena, two main onsets, field-aligned current systems, and plasma flow channels in the ionosphere and in the magnetosphere, J. Geophys. Res.-Space, 122, 4988-5007, https://doi.org/10.1002/2017JA023915, 2017.

Newell, P. T. and Meng, C.-I.: Mapping the dayside ionosphere to the magnetosphere according to particle precipitation characteristics, J. Geophys. Res. Lett., 19, 609-512, https://doi.org/10.1029/92GL00404, 1992.

Newell, P. T., Feldstein, Ya. I., Galperin, Yu. I., and Meng, C.-I.: Correction to "Morphology of nightside precipitation" by Patrick T. Newell, Yasha I. Feldstein, Yuri I. Galperin, and Ching-I. Meng, J. Geophys. Res., 101, 17419-17421, https://doi.org/10.1029/96JA02055, 1996.

Nishimura, Y., Lyons, L. R., Shiokawa, K., Angelopoulos, V., Donovan, E. F., and Mende, S. B.: Substorm onset and expansion phase intensification precursors seen in polar cap patches and arcs, J. Geophys. Res.-Space, 118, 2034-2042, https://doi.org/10.1002/jgra.50279, 2013.

Palin, L., Opgenoorth, H. J., Årgen, K., Zivkovic, T., Sergeev, V. A., Kubyshkina, M. V., Nikolaev, A., Kauristie, K., van de Kamp, M., Amm, O., Milan, S. E., Imber, S. M., Facsko, G., Palmroth, M., and Nakamura, R.: Modulation of the substorm current wedge by bursty bulk flows: 8 September 2002 - Revisited, J. Geophys. Res.-Space, 121, 4466-4482, https://doi.org/10.1002/2015JA022262, 2016.

Pellinen, R. G. and Heikkila, W. J.: Observation of auroral fading before breakup, J. Geophys. Res., 83, 4207-4217, https://doi.org/10.1029/JA083iA09p04207, 1978.

Pulkkinen, A., Amm, O., Viljanen, A., and BEAR Working Group: Ionospheric equivalent current distributions determined with the method of spherical elementary current systems, J. Geophys. Res., 108, 1053, https://doi.org/10.1029/2001JA005085, 2003.

Pulkkinen, T. I., Baker, D. N., Frank, L. A., Sigwarth, J. B., Opgenoorth, H. J., Greenwald ,R., Friis-Christensen, E., Mukai, T., Nakamura, R., Singer, H., Reeves, G. D., and Lester, M.: Two substorm intensifications compared: Onset, expansion, and global consequence, J. Geophys. Res., 103, 15-27, https://doi.org/10.1029/97JA01985, 1998.

Rae, I. J., Murphy,K. R., Watt, C. E. J., Rostoker, G., Rankin, R., Mann, I. R., Hodgson, C. R., Frey, H. U., Degeling, A.
W., and Forsyth, C.: Field line resonances as a trigger and a tracer for substorm onset, J. Geophys. Res., 119, 5343-5363, https://doi.org/10.1002/2013JA018889, 2014.

Rezhenov, B. V.: A possible mechanism for $\theta$ aurora formation, Ann. Geophys., 13, 698-703, https://doi.org/10.1007/s00585995-0698-3, 1995.

Rostoker, G.: Macrostructure of geomagnetic bays, J. Geophys. Res., 73, 4217-4229, https://doi.org/10.1029/JA073i013p04217, 1968.

Rostoker, G., A., Lui, T. Y., Anger, C. D., and Murphree, J. S.: North-south structures in the midnight sector auroras as viewed by the Viking imager, J. Geophys. Res. Lett., 14, 407-410, https://doi.org/10.1029/GL014i004p00407, 1987.

Roux, A., Perraut, S. , Robert, P., Morane, A., Pedersen, A., Korth, A., Kremser, G., Aparicio, B., Rodgers, D., and Pellinen, R.: Plasma sheet instability related to the westward traveling surge, J. Geophys. Res., 96, 17697-17714, https://doi.org/10.1029/91JA01106, 1991.

Ruohoniemi, J. M. and Greenwald, R. A.: The response of highlatitude convection to a sudden southward IMF turning, J. Geophys. Res., 25, 2913-2916, https://doi.org/10.1029/98GL02212, 1998.

Russell, C. T.: How northward turnings of the IMF can lead to substorm expansion onsets, J. Geophys. Res. Lett., 27, 3257-3259, https://doi.org/10.1029/2000GL011910, 2000.

Safargaleev, V., Kangas, J., Kozlovsky, A., and Vasilyev, A.: Burst of ULF noise excited by sudden changes of solar wind dynamic pressure, Ann. Geophys., 20, 1751-1761, https://hal.archivesouvertes.fr/hal-00317372, 2002.

Safargaleev, V. V. and Osipenko, S. V.: Multiple arc-like forms in pulsating and diffuse auroras: ionospheric trace of a substorm trigger?, Adv. Space Res., 28, 1617-1622, https://doi.org/10.1016/S0273-1177(01)00491-4, 2001.

Safargaleev, V. V. and Safargaleeva, N. N.: On the accuracy of highorbiting satellite conjugation with small-scale objects in the ionosphere, Cosmic Res., 56, 115-122, 2018.

Safargaleev, V. V., Mitrofanov, V. M., and Kozlovsky, A. E.: Complex analysis of the polar substorm based on magnetic, optical and radar observations near Spitsbergen, Geomagn. Aeronomy, 58, 793-808, https://doi.org/10.1134/S0016793218040151, 2018.

Saito, T.: Long-period irregular pulsations Pi3, Space Sci. Rev., 21, 427-467, https://doi.org/10.1007/BF00173068, 1978.

Samson, J. C., Wallis, D. D., Hughes ,T. J., Creutzberg , F., Ruohoniemi, J. M., and Greenwald, R. A.: Substorm intensifications and field line resonances in the nightside magnetosphere, J. Geophys. Res., 97, 8495-8518, https://doi.org/10.1029/91JA03156, 1992.

Samsonov, A. A., Sibeck, D. G., Dmitrieva, N. P., and Semenov, V. S.: What Happens Before a Southward IMF Turning Reaches the Magnetopause?, J. Geophys. Res. Lett., 44, 9159-9166, https://doi.org/10.1002/2017GL075020, 2017.

Sarafopoulos, D. V.: Pseudo-field line resonances in ground Pc5 pulsation events, Ann. Geophys., 23, 593-608, https://doi.org/10.5194/angeo-23-593-2005, 2005.

Shevchenko, I. G., Sergeev, V., Kubyshkina, M., Angelopoulos, V., Glassmeier K. H., and Singer H. J.: Estimation of magnetosphere-ionosphere mapping accuracy using isotropy 
boundary and THEMIS observations, J. Geophys. Res., 115, A11206, https://doi.org/10.1029/2010JA015354, 2010.

Sergeev, V. A. and Yahnin, A. G.: The features of auroral bulge expansion, Planet. Space Sci., 27, 1429-1440, https://doi.org/10.1016/0032-0633(79)90089-8, 1979.

Tagirov, V.: Auroral torch structures: results of optical observations, J. Atmos. Terr. Phys., 55, 1775-1787, https://doi.org/10.1016/0021-9169(93)90144-N, 1993.

Tanskanen, E. I.: A comprehensive high-throughput analysis of substorms observed by IMAGE magnetometer network: Years 1993-2003 examined, J. Geophys. Res., 114, A05204, https://doi.org/10.1029/2008JA013682, 2009.

Troitskaya, V. A.: ULF wave investigations in the dayside cusp, Adv. Space Res., 5 , 219-228, https://doi.org/10.1016/02731177(85)90142-5, 1985.

Vasyliunas, V. M.: Theoretical considerations on where a substorm begins, Substorms-4 International Conference on Substorms-4, Lake Hamana, Japan: 9-13 March 1998, edited by: Kokubun, S. and Kamide, Y., Dordrecht, London, Kluwer Academic Publishers, Astrophysics and Space Science library, 238, 9-14, 1998.
Walker, A. D. M.: Excitation of field line resonances by sources outside the magnetosphere, Ann. Geophys., 23, 3375-3388, https://doi.org/10.5194/angeo-23-3375-2005, 2005.

Walker, A. D. M., Greenwald, R. A., Green, C. A., and Stuart, W.: STARE radar auroral observation of Pc5 geomagnetic pulsations, J. Geophys. Res., 84, 3373-3388, https://doi.org/10.1029/JA084iA07p03373, 1979.

Watson, C., Jayachandran, P. T., Singer, H. J., Redmon, R. J., and Danskin, D.: Large-amplitude GPS TEC variations associated with Pc5-6 magnetic field variations observed on the ground and at geosynchronous orbit, J. Geophys. Res.-Space, 120, 77987821, https://doi.org/10.1002/2015JA021517, 2015.

Wright, D. M. and Yeoman, T. K.: CUTLASS observations of a high- $m$ ULF wave and its consequences for the DOPE HF Doppler sounder, Ann. Geophys., 17, 1493-1497, https://doi.org/10.1007/s00585-999-1493-3, 1999. 